\title{
Analysis of reach-scale elevation distribution in braided rivers: definition of a new morphologic indicator and estimation of mean quantities
}

\author{
M. Redolfi, ${ }^{1}$ M. Tubino, ${ }^{1}$ W. Bertoldi, ${ }^{1}$ J. Brasington ${ }^{2}$
}

Corresponding author: M. Redolfi, Department of Civil, Environmental and Mechanical Engineering, University of Trento, Trento, Italy. (marco.redolfi@unitn.it)

${ }^{1}$ Department of Civil, Environmental and

Mechanical Engineering, University of

Trento, Trento, Italy.

${ }^{2}$ School of Geography, Queen Mary

University of London, London, UK.

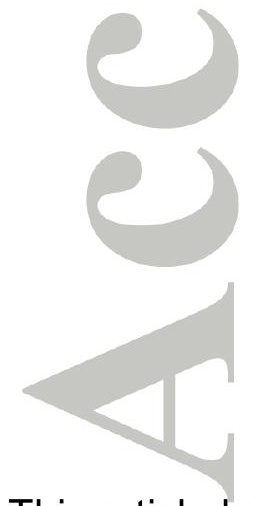

This article has been accepted for publication and undergone full peer review but has not been through the copyediting, typesetting, pagination and proofreading process which may lead to differences between this version and the Version of Record. Please cite this article as an 'Accepted Article', doi: 10.1002/2015WR017918 


\section{Abstract.}

Understanding the role of external controls on the morphology of braided rivers is currently limited by the dearth of robust metrics to quantify and distinguish the diversity of channel form. Most existing measures are strongly dependent on river stage and unable to account for the three-dimensional complexity that is apparent in digital terrain models of braided rivers. In this paper, we introduce a simple, stage-independent morphological indicator that enables the analysis of reach-scale regime morphology as a function of slope, discharge, sediment size and degree of confinement. The index is derived from the bed elevation frequency distribution and characterizes a statistical widthdepth curve averaged longitudinally over multiple channel widths. In this way, we define a "synthetic channel" described by a simple parameter that embeds information about the river morphological complexity. Under the assumption of uniform flow, this approach can be extended to provide estimates of the reach-averaged shear stress distribution, bed load flux and at-a-stationvariability of wetted width. We test this approach using data from a wide range of labile channels including 58 flume experiments and three gravel bed braided rivers. Results demonstrate a strong relationship between the unit discharge and the shape of the elevation distribution, which varies between a U-shape for typical single-thread confined channels, to a Y-shape for multithread reaches. Finally, we discuss the use of the metric as a diagnostic index of river condition that may be used to support inferences about the river morphological trajectory. 


\section{Introduction}

Braided rivers are complex systems, with highly variable and dynamic topography that remains resistant to detailed, deterministic prediction over long temporal scales [Paola, 1996; Paola and Foufoula-Georgiou, 2001]. However, field and laboratory studies have shown that their statistical properties measured at the reach-scale are, in common with single-thread channels, controlled by the characteristic parameters of bankfull discharge, longitudinal slope, and grain size [e.g Mosley, 1983; Robertson-Rintoul and Richards, 1993; Bertoldi et al., 2009a; Ashmore, 2013].

A persistent problem that arises when analyzing the nature of these controls is the definition of robust metrics to quantify the complexity, diversity and evolution of braided river morphology. The most commonly employed morphological measure is the channel count index [e.g. Mosley, 1982; Ashmore, 1991], typically referred to as the braiding index. In its simplest form, this refers to a count of the number of unique channels per cross section. This index can be derived directly from planform imagery or field mapping and provides a first order indication of the intensity of braiding. Along with its related variants (e.g. the bar index, channel length index), this approach has been used frequently to characterize channel response to external forcing in flume experiments [see Egozi and Ashmore, 2008, for a review]. Despite the apparent simplicity of these indices, their measurement is complicated by the strong dependency on discharge [e.g. Surian, 1999; van der Nat et al., 2002; Egozi and Ashmore, 2008]. Specifically, the total number of anabranches for a given morphology typically exhibits a bell-shaped relationship with discharge, peaking at intermediate flows before declining as the whole active belt becomes inundated [Bertoldi et al., 
2009a].

Recent developments in remote sensing, in particular photogrammetry, airborne and terrestrial laser scanning [e.g. Gao, 2009; Marcus and Fonstad, 2010; Brasington et al., 2012] offer the possibility to quantify the fully three-dimensional form of braided channel in unprecedented detail. Yet, despite the increasing availability of such high resolution terrain data, surprisingly little progress has been made in exploiting these data to define new metrics that describe the reach-scale channel morphology in a simple, integrative way. The frequency distribution of elevation, often represented as an hypsometric curve, is widely used elsewhere in geomorphology as a measure of catchment and landform shape and can be parametrized effectively with terrain models [e.g. Willgoose and Hancock, 1998]. In a fluvial context, the frequency distribution of bed elevations have been used to measure the effect of riparian vegetation on the bed topography [Gran and Paola, 2001; Coulthard, 2005; Bertoldi et al., 2011; van Dijk et al., 2013] and bed relief indices [Hoey and Sutherland, 1991; Liebault et al., 2012] used to infer the condition of braided rivers. A systematic analysis of how bed elevation distributions vary in response to characteristics drivers of channel form, such as particle size, discharge, slope, and degree of confinement has, however, yet to be fully established.

Defining the relationship between channel form and the associated driving controls is also relevant for estimating bed load flux and modeling its variation with discharge. Predicting sediment flux in braided networks is notoriously challenging due to the extreme spatial and temporal variability [e.g. Thompson, 1985; Davies, 1987; Young and Davies, 1990, 1991; Shvidchenko and Kopaliani, 1998]. Moreover, due to the co-related spatial variability of bed topography and hydraulic forces, attempts to predict flux using standard transport 
formulas applied with cross-sectional averaged data are often unreliable [Carson and Griffith, 1987; Ashmore, 1988; Griffith, 1989]. Several studies [Paola, 1996; Nicholas, 2000; Ferguson, 2003; Bertoldi et al., 2009b] have highlighted the need to account for the full spatial distribution of bed shear stress (or flow depth) in order to quantify the total bed load flux effectively. However, the relation between the reach-scale average bed elevation distribution and bed load transport has yet to be investigated fully. Such an analysis would also shed light on the role of local flow acceleration and energy gradients as factors influencing sediment transport at the reach-scale.

In this paper, we introduce a novel, parsimonious, geometric model to quantify reach-scale bed morphology. This simple model is described by one key parameter and we show how it can be used to differentiate the role of longitudinal slope, grain size, discharge, as well as presence of vegetation and lateral confinement on the morphology of braided rivers. The novelty of the approach lies in the spatial scale of the analysis, which focuses on reach-averaged rather than cross-sectional morphology. This reflects a desire to establish these key functional relationships at a representative continuum scale that integrates the extreme spatial variability evident when multi-thread rivers are viewed as set of cross sections [see Ashmore, 2013]. The proposed model is computed purely from the threedimensional bed topography so that the description of channel form is independent of discharge. The method is moreover timely, as it takes advantage of the new generation of 3D datasets that are emerging from a revolution in survey methods and geomatics [Brasington et al., 2012]. Furthermore, as the model makes no prior assumptions concerning the shape of the elevation distribution, it can be applied to both single-thread and multithread channels. As a result, it provides a diagnostic index of river condition and can be 
used to support the interpretation of river morphological evolution.

Following a detailed description of the model, we examine how the approach can be used to improve understanding of the at-a-station variability of the principle hydraulic parameters, e.g. wetted width, shear stress, width-to-depth ratio and bed load flux. This is achieved by applying a simple uniform flow model using the resulting spatially-averaged section as the topographic boundary condition. Results from this approach are presented for a wide range of braided channels, using data from a combination of physical experiments, field observations and depth-averaged numerical models.

\section{Methods}

\subsection{Definitions and scaling}

The model we propose is based on a reach-scale geometric parameter that is derived from a curve which represents the cumulative distribution of the bed elevation. Here we illustrate how this distribution is obtained, we identify the most important controlling factors and define the scaling relationships needed to obtain dimensionless (i.e. scale independent) relationships between the external controls and the reach-averaged morphology. As sketched in Figure 1, we first consider a cross section of longitudinal position $x$ and we measure $b_{x}$, the width of the section lying below a projected water surface (stage), $D$, measured with respect to the lowest elevation obtained on that section. This equates graphically to the cumulative length of the horizontal segments of Figure 1a. Increasing $D$ from 0 to the highest elevation on the cross section we obtain the $b_{x}(D)$ curve.

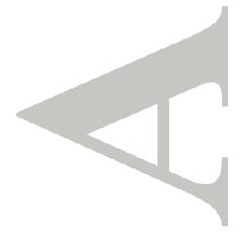


The same calculation is now repeated for all available sections within a reach and then by averaging we obtain the curve:

$$
b(D)=\frac{1}{L} \int_{0}^{L} b_{x}(D) d x
$$

where $L$ is the reach length and $x$ is the longitudinal coordinate. The $b(D)$ relation is a reach-averaged width-depth curve, but it also represents a cumulative frequency distribution of bed elevation, as far as it indicates the area that lies below the elevation $D$. As discussed below in section 3.1, this curve can be conveniently approximated as a power law, in the form:

$$
b=k D^{\alpha}
$$

where $k$ defines the scale of the width and the exponent $\alpha$ characterizes the shape of the averaged cross section.

A similar approach was used in the context of estuarine morphology by Toffolon and Crosato [2007], who adopted the power law approximation (2) to identify three different section types on the basis of the concavity of this curve and described effectively by the value of $\alpha$. These are U-shaped, for a classic cross section with concave upward shape $(\alpha<1)$; V-shaped, for triangular shape $(\alpha \simeq 1)$; Y-shaped, for a concave downward shape $(\alpha>1)$.

For the case of a single-thread river, the $b(D)$ curve has a straightforward geometrical significance, because it simply represents the shape of one half of the cross section. Form this perspective, equation (2) is analogous to previous analytical functions that have been used to describe the cross-sectional shape of regime channels [e.g. Glover and Florey, 1951]. 
For multi-thread rivers, however, the actual cross section geometry is complex and varies longitudinally. Nonetheless, we can consider the $b(D)$ curve as an statisticallyequivalent average cross section, in which the elevation values have been sorted in rank order. According to this approach we can define the depth, $h$, for the equivalent averaged bed elevation, $\eta$ (Figure 1b). Moreover the $b(D)$ curve has an hydraulic significance because it represents a width-depth curve indicating how the free surface width varies with water depth.

Different styles of cross sections and the corresponding reach-averaged representation are illustrated in Figure 2.

To investigate the relationship between the shape of this "average cross section" and the river characteristics, it is necessary to identify which dimensionless parameters are relevant controls on channel form. If we assume that the reach-averaged properties of braided networks depend on external controls in a deterministic way [e.g. Egozi and Ashmore, 2008], and we assume the existence of equilibrium conditions with constant discharge $Q$, uniform valley slope $S$, and constant confinement width $W$ (defined as the distance between fixed or relatively stable banks), the $b(D)$ curve and the average bed load flux Qs depend on the following parameters:

$$
\{b(D), Q s\}=f\left(Q, S, W, \rho, \rho_{s}, g, d_{s}\right),
$$

where $\rho$ and $\rho_{s}$ are water and sediment density, $g$ is gravitational acceleration, and $d_{s}$ is a representative grain size, here assumed to be constant throughout the reach.

Through the $\pi$-theorem [Barenblatt, 1996], the number of parameters can be reduced by writing the functional dependence in dimensionless form:

$$
\left\{b^{*}\left(D^{*}\right), Q s^{*}\right\}=f\left(Q^{*}, S, W^{*}, \Delta\right),
$$


where lengths are scaled by $d_{s}$, namely:

$$
b^{*}=\frac{b}{d_{s}}, \quad D^{*}=\frac{D}{d_{s}}, \quad W^{*}=\frac{W}{d_{s}},
$$

and the scaled solid and liquid discharges are expressed, following Einstein [1950]; Parker et al. [2007], as:

$$
Q s^{*}=\frac{Q s}{\sqrt{g \Delta} d_{s}^{5 / 2}}, \quad Q^{*}=\frac{Q}{\sqrt{g} d_{s}^{5 / 2}},
$$

where $\Delta=\left(\rho_{s}-\rho\right) / \rho$ is the relative submerged weight of the sediment.

The relationship in equation (4) is independent of scale and it is expected to hold insofar as the braided network is large enough to avoid the so-called "scale effects" induced by water viscosity (e.g. ripples), surface tension or cohesion of the bed material [e.g. Young and Warburton, 1996].

These conditions are readily met in the laboratory, but for natural gravel bed rivers, the effects of discharge variability, vegetation and the sorting of bed material are needed to fully describe braided river morphodynamics.

In the following, we will refer to the parameters in equation (4) neglecting the effect of sediment density as natural minerals show limited variability. This simplifies the morphodynamic response of braided rivers to just three parameters $Q^{*}, S$, and $W^{*}$.

\subsection{The average section method for estimating bed load flux}

The definition of a reach-averaged section to represent the complexity of channel morphology also provides a tool to predict information about the hydraulic geometry and response of bed load transport to variations of water discharge, accounting for the spatial variability of the flow over the complex morphology.

Following an approach similar to [Bertoldi et al., 2009b] we assume that the effect of 
spatial accelerations and local variations of the energy gradient on the Shields stress are negligible, at least in an averaged sense. Therefore, we can estimate the hydraulic parameters and the bed load flux using a simple 1D numerical computation under the hypothesis of locally uniform flow (with the mean longitudinal slope) and horizontal free surface in the equivalent, average section of Figure $1 \mathrm{~b}$.

By integrating the uniform flow formula across the average section we obtain, in dimensionless form:

$$
Q^{*}\left(D^{*}\right)=\int_{0}^{b^{*}} C \sqrt{S} h^{* 3 / 2} d y^{*}
$$

where $y^{*}$ is the transverse coordinate and $h^{*}$ is the local flow depth along the cross section (see Figure $1 \mathrm{~b}$ ), both scaled with $d_{s}$, and $C$ is the Chèzy coefficient that can be calculated as a function of $h^{*}$ according to a resistance law such as Engelund and Fredsoe [1982] or using the Manning formula.

Similarly, we can estimate the sediment discharge using a standard formula for computing the local bed load flux per unit width:

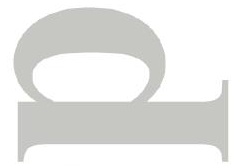

$$
q s=\sqrt{g \Delta} d_{s}^{3 / 2} \Phi(\theta)
$$

[e.g. Meyer-Peter and Müller, 1948; Parker, 1990], where $\Phi(\theta)$ is a function of the local Shields stress $\theta$ which, under the hypothesis of locally uniform flow and using a single value of grain size, gives:

$$
\theta=\frac{S h^{*}}{\Delta}
$$

Integrating equation (8) along the average section gives, in dimensionless form:

$$
Q s^{*}\left(D^{*}\right)=\frac{1}{\sqrt{g \Delta} d_{s}^{5 / 2}} \int_{0}^{b} q s d y=\int_{0}^{b^{*}} \Phi(\theta) d y^{*}
$$


Combining equations (7) and (10) provides a method for estimating the reach-averaged bed load flux as a function of the water discharge.

In the following section, the predictive performance of this procedure is tested against bed load flux data from laboratory measurements and numerical simulations.

\subsection{Flume experiments data}

Three sets of laboratory experiments were used to investigate the value of morphological index $\alpha$ of equation (2) in differentiating the morphodynamic response of braided channel under a range of forcing conditions.

The experiments were performed at the Hydraulic Laboratory of the University of Trento and include 58 individual experimental runs, with a wide range of conditions of slope, discharge, confinement width, and grain size [see Bertoldi et al., 2009b; Welber et al., 2013; Garcia Lugo et al., 2015, for further details]. The flume measured $25 \mathrm{~m}$ long by $2.9 \mathrm{~m}$ wide with a bed comprising well-sorted sand, leveled initially to the prescribed longitudinal gradient. To explore the effect of confinement, the channel width was set by placing equally-spaced straight banks inside the flume. Each run was performed with constant water and sediment supply. The sediment efflux was weighed using a system of load cells and the bed topography measured on a regular grid using a gantry-mounted point laser scanner. The sediment feed was adjusted in order to maintain a long-term mass balance, while the duration of each run was set according to the unit transport rate and ranged from 1.5 to $110 \mathrm{~h}$, to allow the system to reach a state of statistical equilibrium.

The first series of runs hereafter named TN1 [see Bertoldi et al., 2009b] encompassed five different bed slopes (with gradients in the range $0.3-1.7 \%$ ) and various water discharges. The bed material comprised well-sorted sand with a median size of $0.63 \mathrm{~mm}$. The second 
experimental set, TN2 [see Welber et al., 2013] incorporated five runs, with fixed discharge and slope and a bed with a coarser grain size $(1 \mathrm{~mm})$. The role of network confinement was investigated in experiment TN3 [Garcia Lugo et al., 2015], in which different combinations of flume width and discharge were analyzed. Longitudinal gradient and median grain size were $1.0 \%$ and $1.0 \mathrm{~mm}$, respectively.

A summary of laboratory experiments is given in Table 1.

\subsection{Field data}

Existing data from three contrasting natural gravel bed rivers were also used in this study: the Sunwapta, Canada; the Tagliamento, Italy; and the Rees, New Zealand. The Sunwapta River is a small pro-glacial, gravel bed braided river in Alberta, Canada [see Ashmore et al., 2011]. The data used here are a set of 16 cross sections, surveyed repeatedly during August 1999. The sections extend over a $150 \mathrm{~m}$ long reach, which corresponds to approximately one braidplain width. The valley gradient is $1.5 \%$ and the mean sediment size is around $40 \mathrm{~mm}$. The peak daily discharge varies diurnally in response to upstream glacier melt, and over the relevant 17 day period associated with the data acquisition varied from 8 to $18 \mathrm{~m}^{3} \mathrm{~s}^{-1}$, with significant morphological activity observed only when the peak discharge exceeded $13 \mathrm{~m}^{3} \mathrm{~s}^{-1}$.

The Tagliamento River is a large gravel bed braided river in North-East Italy. This analysis focuses on a $21 \mathrm{~km}$ long reach, for which a $2 \mathrm{~m}$ resolution DEM is available derived from an airborne lidar survey in May 2005 [Bertoldi et al., 2011]. The braidplain width is highly variable, due to the occurrence of geological constraints, and ranges from 200 to $1000 \mathrm{~m}$. The longitudinal gradient is $0.35 \%$ and does not vary significantly throughout

the reach. Similarly, there are no major trends in surface grain size, though this exhibit 
large local variability, with $d_{50}$ typically $45 \mathrm{~mm}$ in the main anabranches and $25 \mathrm{~mm}$ on exposed bars. A bulk value of $d_{50}=35 \mathrm{~mm}$ was used to compute the dimensionless parameters. Estimates of discharge through the study reach are associated with large uncertainty, due to the difficulty of establishing a reliable stage-discharge relationship for this labile system. An approximation is provided by Bertoldi et al. [2010] who suggest that the 3-year return period discharge is around $1700 \mathrm{~m}^{3} \mathrm{~s}^{-1}$. Moreover analysis of planform imagery Welber et al. [2012] indicates that $90 \%$ of the braidplain is inundated for flows of $1000 \mathrm{~m}^{3} \mathrm{~s}^{-1}$

The third study case is a $2.5 \mathrm{~km}$ long braided reach of the Rees River in the Southern Alps of New Zealand, surveyed as part of the ReesScan project [Brasington, 2010]. Detailed topographical measurements were acquired after 10 storm events in the period October 2009-May 2010 using a combination of terrestrial laser scanning for exposed bed topography and optically-derived bathymetry. Approximately $10 \%$ of the channel bed was submerged at low flow [Williams et al., 2014]. The exposed and bathymetric models were fused to generate a $0.5 \mathrm{~m}$ resolution DEM with an estimated vertical standard deviation of the error of $0.007 \mathrm{~m}$ for exposed bars and $0.089 \mathrm{~m}$ for inundated area [Williams et al., 2014]. Braidplain width varies between $250-700 \mathrm{~m}$. The average gradient is $0.57 \%$, and the grain size is characterized by $d_{50}=20 \mathrm{~mm}$ and $d_{90}=41 \mathrm{~mm}$ [Williams et al., 2014]. Discharge was estimated from rated stage measurements in a relatively stable, single-channel section located a few kilometers upstream. This site was monitored for 18 months between 2009 - 2011 and during that period the maximum flow recorded was $475 \mathrm{~m}^{3} \mathrm{~s}^{-1}$ while flows of $300 \mathrm{~m}^{3} \mathrm{~s}^{-1}$ were exceeded for approximately $10 \mathrm{~h}$. Summary descriptions of the three rivers are reported in Table 2. 


\subsection{Numerical modeling}

In order to explore the connection between the reach-scale morphology, as described through the $b(D)$ curve, and the bed shear stress distribution, we performed a set of fixed-bed numerical simulations. Specifically, we used the 2D depth-averaged hydrodynamic model Delft3D [see Schuurman et al., 2013; Williams et al., 2016] to compute the distribution of the hydraulic parameters for the Rees River. The model was parametrized based on the published setup, calibration, and validation described by Williams et al. [2013].

Two sets of simulation scenarios were considered. In the first, constant discharges $\left(200 \mathrm{~m}^{3} \mathrm{~s}^{-1}\right.$ and $\left.323 \mathrm{~m}^{3} \mathrm{~s}^{-1}\right)$ were maintained until the system attained a steady-state solution, in order to characterize the frequency distribution of flow depth and bed shear stress.

In the second set, the at-a-station response to varying discharge was simulated by slowly rising discharge from $30 \mathrm{~m}^{3} \mathrm{~s}^{-1}$ to a peak flow of $430 \mathrm{~m}^{3} \mathrm{~s}^{-1}$. In order to avoid inertial effects as well as delays due to propagation of flow pulse throughout the channel network, we applied a slow $\left(6 \mathrm{~m}^{3} \mathrm{~h}^{-1}\right)$ linear growth of the discharge. In this way the solution evolves through a sequence of quasi-steady states, which depend only on the instantaneous discharge.

\section{Results}

The three sets of laboratory experiments, the field data, and the numerical results provide information about the topographic configuration of different braided networks and here we illustrate how $b(D)$ curves can be used to investigate the relation between channel form and controlling factors. 
Calculation of the reach-scale index $\alpha$ requires a preliminary assessment of the data quality and quantity needed to build sufficiently robust statistics [Egozi and Ashmore, 2008]. Unlike other forms of terrain analysis, such as sediment budgeting [Wheaton et al., 2010], the reach-averaged index is only weakly sensitive to random measurement errors, which tend to be filtered by averaging the geometry over a large number of sections. Conversely, its estimate is sensitive to systematic bias, especially estimates of deepest (or rather lowest) channel which is used as reference datum.

Incorporating a sufficient number of cross sections is fundamental for estimating any reach-scale property. However, the relevant quantity is not the number of cross sections, but rather the longitudinal extension of the reach. This is confirmed by the analysis of laboratory data which reveals $b(D)$ is not strongly dependent to the density of sections so long as the $x$-resolution (spacing) is not less than the mean channel width. By contrast, the longitudinal extension of the survey is important as this is necessary to provide a statistically representative sample of the morphological variability at the reach-scale. This longitundinal sampling interval is linked to the characteristic length scale of the braided network and will, therefore, scale with the main channel width [Hundey and Ashmore, 2009].

\subsection{The average section of relatively unconfined networks}

The self-formed braided networks established in the TN1 and TN2 experiments were relatively unconfined. Consequently, we expect that the effect of the flume width $W^{*}$ is negligible, and that the morphological response depends, according to equation (4), on $Q^{*}$ and $S$ alone.

Figure 3a illustrates the $b(D)$ curves for these two sets of runs, computed as an average of 
the bed topography at the end of each experimental run. All curves exhibit a characteristic Y-shape, as opposed to the typical U-shaped cross section of single-thread rivers. TN1 and TN2 experiments are directly comparable, because the effect of the different grain size ( $0.63 \mathrm{~mm}$ and $1 \mathrm{~mm}$, respectively) is filtered by the use of normalized variables (equation $(5))$.

The form of the curves shown in Figure 3a highlights the dominant control of channel slope $S$, with steeper channels exhibiting flatter curves (i.e. those with a smaller $D^{*}$ at the endpoint) and therefore indicating less topographic variability. The relationship between slope and bed relief can be analyzed further by computing a bed relief index for each section [Hoey and Sutherland, 1991; Liebault et al., 2012], here scaled using the sediment size:

$$
B R I_{x}^{*}=\frac{1}{W^{*}} \int_{0}^{W^{*}}\left(\eta^{*}-\bar{\eta}^{*}\right)^{2} d y^{*}
$$

where $\eta^{*}$ indicates the scaled bed elevation and $\bar{\eta}^{*}$ is the cross-sectional mean elevation. Averaging equation (11) in the longitudinal direction $x$ gives the reach-averaged bed relief index $B R I^{*}$ illustrated in Figure 4. This suggests that while there is no significant dependence on discharge, the bed relief is clearly inversely correlated with the slope.

The exponent $\alpha$ can be determined for each experiment by fitting equation (2) to the $b(D)$ relationship. Figure 5 illustrates the resulting relationship between the reach-scale index of channel form $(\alpha)$ and the scaled discharge. The index exhibits a strong inverse correlation with $Q^{*}$ for the TN1 and TN2 experiments (open symbols) with a variance $\sigma^{2}=0.013$ with respect to a linear regression.

Similar results are also obtained from the field observations. The Sunwapta River is characterized by dimensionless parameters similar to those of the TN1 and TN2 exper- 
iments. For example, the observed range of morphologically active discharges of the Sunwapta, $Q=13-18 \mathrm{~m}^{3} \mathrm{~s}^{-1}$, gives $Q^{*}=1.3-1.8 \cdot 10^{4}$, which is approximately the value adopted in most of the TN1 runs where $S=1.3-1.7 \%\left(Q^{*}=1.6 \cdot 10^{4}-2.2 \cdot 10^{4}\right.$ for 10 on 14 runs). In addition, the braidplain width is similar (in dimensionless form) to one of the TN1 experiments $\left(W^{*} \simeq 3.8 \cdot 10^{3}\right.$ and $W^{*} \simeq 4.6 \cdot 10^{3}$, respectively). Figures 3a,b reveal that the $b^{*}\left(D^{*}\right)$ curve of the Sunwapta lies between the $S=1.3 \%$ and the $S=1.7 \%$ curves of the TN1 experiments, which confirms similarity of the bed elevation distributions between braided networks having different scales but comparable dimensionless controls $S, Q^{*}$ and $W^{*}$. The relationship between the bed relief index and the power law exponent $\alpha$ (reported in Figures 4 and 5 with the "X" symbol) is also similar to that observed for the experimental bed distributions.

The Rees and the Tagliamento Rivers have strongly contrasting discharge and river width characteristics. In the case of the Rees, if we consider a representative discharge $Q=300 \mathrm{~m}^{3} \mathrm{~s}^{-1}$, we obtain a scaled value $Q^{*}=1.7 \cdot 10^{6}$, that is two orders of magnitude larger than that of the flume experiments. Similarly, for the Tagliamento, assuming $Q=1000 \mathrm{~m}^{3} \mathrm{~s}^{-1}$ as a representative discharge, gives $Q^{*}=1.4 \cdot 10^{6}$. This affects $b^{*}$, which reaches maximum values one order of magnitude larger than in the case of the experimental data. On the other hand, the normalized depth $D^{*}$ is only slightly larger. The character of the Tagliamento is further confounded by the effects of geological controls and vegetated islands on local confinement [Gurnell et al., 2001; Bertoldi et al., 2011]. To account for this macro-scale variability, we divided the $21 \mathrm{~km}$ long reach into 12 comparatively homogenous sub-reaches characterized by similar patterns of valley confinement and vegetation density (see Figure 6a). 
The $b(D)$ relationship for each sub-reach of the Tagliamento and the Rees are reported in Figures $6 \mathrm{~b}$ and $6 \mathrm{c}$. The Rees and most sub-reaches of the Tagliamento exhibit a similar morphology, with a Y-shaped average cross section characterized by a power law exponent $\alpha$ in the same range as for the laboratory experiments $(1.5-2.5)$. A few sub-reaches of the Tagliamento (in particular 8 and 9) are described by a different shape, with subreach 9 displaying a U-shaped configuration and a value of $\alpha<1$. As discussed in the next section, such morphological difference is most likely related to the effect of lateral confinement.

It is worth noticing that the agreement between the power law (2) and the computed $b(D)$ curves is generally strong, both for field and laboratory (TN1 and TN2) data, insofar as the coefficient of determination $\left(R^{2}\right)$ is usually larger than 0.97 (see Figure 7 ). Consequently, the choice of the representative discharge used to define the upper limit of the $b(D)$ curves for the field data affects the best fitting coefficient $\alpha$ only marginally. For example a $\pm 25 \%$ variation of the discharge in the Tagliamento River (from 750 to $1250 \mathrm{~m}^{3} \mathrm{~s}^{-1}$ ) leads to changes of $\alpha$ within $\pm 3 \%$ for the unconfined zones and up to $\pm 7 \%$ for the highly confined sub-reaches 8 and 9 .

\subsection{Effect of river confinement}

To explore the effect of the network confinement on the cross section shape, we consider a third set of laboratory experiments, identified by the code TN3 in Table 1 . These data are then compared to the observations on the Tagliamento River.

The TN3 experiments were designed to simulate morphodynamic response across a wide range of channel widths, varying from 0.15 to $1.5 \mathrm{~m}$. This was intended to reproduce the transition from single-thread to braided channel configurations. The $b(D)$ curves for the 
runs with a discharge equal to $2 \mathrm{ls}^{-1}$ are reported in Figure 8, which illustrates the resulting average section geometry. In the case of the wider runs, the curves clearly resemble the Y-shape of the previous experiments. Moreover, as the degree of confinement is increased, the $b(D)$ relation becomes less curved (decreasing $\alpha$ ): for the run with $W=0.6 \mathrm{~m}$ it shows an almost linear trend ( $\alpha \simeq 1, \mathrm{~V}$-shaped average section of Figure 2), while the narrower runs are characterized by U-shaped cross sections and values of $\alpha<1$.

To quantify the role of the confinement, values of $\alpha$ are plotted as a function of the unit discharge $Q^{*} / W^{*}$ in Figure 9. This figure incorporates the data from all laboratory experiments TN1, TN2, and TN3. The results indicate a strong inverse relationship in which higher values of $\alpha$ are associated with lower values of the unit discharge (non-confined channels), and U-shaped configurations $(\alpha<1)$ with normalized unit discharge larger than approximately 50. TN3 experiments with larger flume width (lower $Q^{*} / W^{*}$ ) align with the TN1 and TN2 runs, showing only a minor effect due to the different discharge and slope. A few of the TN1 runs are characterized by higher values of $\alpha$ compared to the TN3 runs with the same unit discharge (points with $Q^{*} / W^{*}$ approximately $20-30$ ). As highlighted in Figure 7 the power law fitting of the most confined TN3 experiments is less accurate, due to presence of nearly vertical sidewalls; however, the exponent $\alpha$ retains its primary meaning as an indicator of the curve concavity.

The same variables are used in Figure 9 for the field data, where data from the Tagliamento refer to the same sub-reaches as shown in Figure 6. This suggests a similar trend, despite the larger scatter which relates, mostly likely, to the unquantified effects of vegetation and variable discharge. Specifically, the large variability of discharge on the Rees and Tagliamento makes the position of the points along the horizontal axis dependent on the 
choice of the representative discharge. Despite this uncertainty, the relevant observation is that network confinement it quantified by a decrease of $\alpha$ similar to that exhibited in the TN3 experiments. Such specific sensitivity of the exponent $\alpha$ to the degree of confinement highlights its value as a diagnostic index of morphological condition.

\subsection{Estimation of bed load flux}

The results of the above analysis can be used to estimate, in a simplified manner, the bed load flux and the inundation dynamics of braided river networks. Specifically, here we use the two-dimensional hydraulic models of the Rees River to test the hypothesis that a simple 1D, uniform flow approach applied on a representative average section can reproduce the statistical variability of the bed shear stress over complex braided topography. Results from the 2D numerical simulations suggest that at peak discharge a relatively large area of the Rees River reach is active and experiences a highly variable distribution of the bed shear stress, ranging from $\theta>0.2$ in few small regions to $0.038<\theta<0.05$ over approximately $40 \%$ of the active area. By comparison, the predicted stress distribution derived from a 1D uniform flow model applied using the average section method is shown in Figure 10a; modeled here for a peak flood $\left(Q=323 \mathrm{~m}^{3} \mathrm{~s}^{-1}\right)$ and for an intermediate discharge $\left(Q=200 \mathrm{~m}^{3} \mathrm{~s}^{-1}\right)$. Figure 10b illustrates the increase of reach-averaged wetted width and bed load flux with the discharge for both models.

There is a close degree of agreement between the spatially-explicit numerical simulations and the average section method, although the average section method tends to over-predict higher values of shear stress, and therefore overestimate the reach-averaged sediment flux, especially at low discharges. This benchmarking exercise suggests that the average section method is able to account for the spatial variability of shear stress, and thus provides 
effective spatially-averaged estimates of bed load as a function of discharge.

The depth-integrated numerical hydrodynamic simulations, only account for the 3D flow field in a highly simplified, parameterized way [Nicholas et al., 2013]. This is likely to lead to errors in the local stress predictions, particularly in areas of intense helical flow, such as at confluences and areas of high curvature. However, comparison of numerical solutions with and without the simplified closure model reveals that, although significant differences are locally observed, the overall stress distribution is nearly unchanged. This suggests that the 3D effects are negligible when studying the problem at the reach-scale, and thus the 1D averaged approach may provide robust statistical insights.

Similarly, local effects such as flow accelerations, differences in the energy slope, and variations of the water surface elevation between different anabranches appear of secondary importance when averaging along the reach. However, such local processes are not completely negligible. For example, scour pools are often associated with low energy gradients [Nicholas, 2000], and the uniform flow assumption tends to overestimate the flux in deep areas of confluences [Martín-Vide et al., 2015]. Conversely, there are shallow areas (i.e. bar fronts) where the high energy slope generates a relatively intense stresses that cannot be represented. Figure 10a indicates that the average section method tends to over-predict the higher values of shear stress, especially at $Q=200 \mathrm{~m}^{3} \mathrm{~s}^{-1}$, which leads to overestimation of the reach-averaged sediment flux, particularly at low discharges, as illustrated in Figure 10b.

A further test comes from the bed load flux measured in TN1 experiments. Figure 11 shows observed sediment flux against estimates from the average the section method and from the model by Bertoldi et al. [2009b], both computed using the established Parker 
[1990] bed load transport formulation.

Slight variations in the predicted flux are possible for alternative bed load transport models, although these are likely only to scale the magnitude of the flux and thus preserving the basic relationship.

\subsection{At-a-station variability}

Bertoldi et al. [2009b] used a simple 1D model to explore the at-a-station variability, namely the response to discharge variations that are fast enough not to produce significant morphological changes (i.e. assuming a fixed bed). The validity of Bertoldi et al.'s [2009b] results has not yet been tested directly due to a lack of data.

Here we extend this earlier analysis, and use the average section method to predict the at-a-station response and compare these results with those obtained using the Delft3D simulations of the Rees River and discharge-inundation area relationships obtained photogrammetrically for a reach of the Tagliamento. Figure 10b illustrates the predicted pattern of wetted width with increasing discharge based on both fixed-bed Delft 3D simulations of the Rees River, and those obtained using the average section method. There is a close correspondence between the predicted pattern of wetted width to discharge (dashed lines) for both models, again suggesting that the simple distribution function model is able to account for the effects of complex topography without the need for spatially-explicit modeling.

Approximating the $b(D)$ curves as a power law also enables an analytical solution to the at-a-station variability for various relevant hydrodynamic parameters. Adopting the Manning formula for the flow roughness, the cross-section integral of equation (7) can be 
written as:

$$
Q^{*}=\frac{\sqrt{S}}{n \sqrt{g} d_{s}^{1 / 6}} \int_{0}^{b^{*}}\left(D^{*}-\eta^{*}\right)^{5 / 3} d y^{*}
$$

where $n$ is the Manning coefficient. Considering the average section expressed by the power law (2), it is possible to compute analytically the integral above. The resulting discharge-stage relation has the form:

$$
Q^{*} \propto D^{* 5 / 3+\alpha},
$$

which reveals, in the case of relatively high values of the exponent $\alpha$, a remarkably strong dependence of the discharge on the water depth. Inverting equation (13) and using equation (2) it is then possible to express the width as a power low function of discharge, in the form:

$$
b^{*} \propto Q^{* \varphi}, \quad \text { where } \varphi=\frac{3 \alpha}{5+3 \alpha} .
$$

According to equation (14) the exponent $\varphi$ is higher in complex (larger $\alpha$ ) sections, ranging from $\varphi \simeq 0$ (U-shaped section) to $\varphi=1(\alpha \rightarrow \infty)$. For example, when this approach is applied to sub-reaches 3 and 7 of the Tagliamento River (see Figure 6) it gives $\varphi=0.45$ and $\varphi=0.52$, which is consistent with the exponent measured in the same reaches by Welber et al. [2012] ( $\varphi=0.52$ and $\varphi=0.53$ respectively).

If we denote with the zero subscript the flow variables in formative conditions, we can visualize how the inundation curves depends on the coefficient $\alpha$ as reported in Figure 12a, which shows how Y-shaped sections (larger values of $\alpha$ ) are associated to a more linear relationship.

Similarly the width-to-depth ratio

$$
\beta=\frac{b^{*}}{D^{*}} \propto Q^{\frac{3 \alpha-3}{3 \alpha+5}}
$$


shows a remarkably strong dependence on $\alpha$ (Figure 12b). Small values of $\alpha$ result in a width-to-depth ratio that decreases for increasing discharge, a configuration typical of single-thread rivers. By contrast, unconfined braided networks $(\alpha>1)$ are characterized by increasing values of $\beta$.

In addition, the response of the transport rate to changing discharge can be evaluated by assuming a simple bed load formula of the type:

$$
\Phi(\theta)=c\left(\theta-\theta_{c r}\right)^{\delta}
$$

[e.g. Meyer-Peter and Müller, 1948; Wong and Parker, 2006], which through equation (10) leads to

$$
Q s^{*} \propto\left(\theta^{D}-\theta_{c r}\right)^{\alpha+\delta}, \quad \theta^{D}=\frac{S D^{*}}{\Delta}
$$

where $\theta_{D}$ is the Shields stress in the deepest point of the average section and $\theta_{c r}$ indicates the critical threshold for sediment motion. Due to the presence of this threshold, equation (17) is not tractable as a simple power law and setting $\alpha$ alone is insufficient to obtain a unique relationship once the variables are normalized. Therefore, we need to define the bed load flux at the formative condition $Q s_{0}$. This can be done by fixing $\theta_{c r}=0.047$ and setting $\theta_{0}^{D}$ to obtain a given mean Shields stress for formative conditions, which can be computed as follows:

$$
\bar{\theta}_{0}=\frac{1}{b^{*}} \int_{0}^{b^{*}} \theta_{0} d y=\frac{\theta_{0}^{D}}{\alpha+1}
$$

For example, setting $\bar{\theta}_{0}=0.06$ leads to set of curves illustrated in Figure 12c, which demonstrate that higher $\alpha$ values lead to a linear response to flow variations and to a remarkably small threshold for sediment motion. This result differs markedly from the 
behavior of U-shaped sections, which show a strongly nonlinear behavior in the region close to the threshold for sediment motion.

\section{Discussion}

The reach-scale morphological metric or indicator, $\alpha$, describes the form of an elevation distribution function, measured with respect to the lowest point on individual sections. When compared to existing metrics used to characterise braiding, it offers a number of significant advantages. For example, classic braiding indices [e.g., as discussed by Egozi and Ashmore, 2008] are highly dependent on discharge and moreover, difficult to measure as they require careful definition of "where the water margin is" and "what a channel is", all inevitably ambiguous decisions based on data resolution and user interpretation [Marcus and Fonstad, 2010]. Conversely our indicator is stage-independent and is defined directly from topographic data. Most importantly, our index incorporates the key information about the topographical heterogeneity of the braided network, that are the vital ingredients to quantify at-a-station variability and bed load flux. Despite these advantages, the index is built to support rather than replace exsiting braiding indices, which remain relevant largely due to their intuitive characterization of the channel network topology. Compared with other methods based on the hypsometric curves, evaluation of the elevation with respect to the deepest point along the cross section, has several advantages. Besides accounting for the reach-scale stress distribution, it also enables estimation of width-to-depth curves which moreover have a simple shape that can be conveniently represented by a power law.

In the following discussion, we examine step-by-step the key results obtained from the

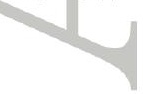


above analyses, providing possible explanations and highlighting the relevant limitations of the proposed method.

\subsection{Key controls of reach-averaged morphology}

The results above provide a rich, albeit not exhaustive, insight to the effect of the relevant controls on river form and process, in particular slope, discharge, sediment size and degree of confinement.

The observed similarity between braided networks at different scales confirms the capability of the Froude-scaled models to reproduce quantitatively the morphodynamics of large gravel bed rivers [Ashmore, 1982; Hoey and Sutherland, 1991]. This justifies the assumption of the dimensionless (i.e. scale independent) functional relation, equation (4), where the grain size $d_{s}$ (as well as the gravitational acceleration $g$ ) is incorporated in the definition of the dimensionless groups. In this way the number of independent variables is reduced by two, so that the morphological configuration is expected to depend only on $S, Q^{*}, W^{*}, \Delta$. Neglecting the effect of $\Delta$ is motivated by the fact that the sediment density does not vary much among the most common river minerals, so that it is probably not a significantl control on the morphological response.

A critical insight relates to the observation that an inverse relationship exists between the bed relief and channel slope (Figure 4). A possible interpretation of this relates to the tendency for gravel bed rivers to maintain a Shields stress not far from the critical value for sediment motion (so called threshold channels [Parker et al., 2007]). Indeed, if we consider that the average stress is proportional to the mean water depth multiplied by the slope, it is not surprising that the channel depth responds inversely to variations of the topographic gradient. 
Our analysis of the average section is focused principally on its shape (expressed through the coefficient $\alpha$ ) rather than on a complete description of its response to varying regime conditions. A more comprehensive investigation requires analysis also of the scale coefficient $k$ of the power law approximation (2), which depends on both the horizontal and vertical scale of the curves. This can be expressed as:

$$
k=\frac{b_{0}}{D_{0}^{\alpha}}
$$

with $b_{0}$ indicating the wetted width in formative conditions and $D_{0}$ the corresponding point on the curve. We have seen that $D_{0}$ is largely dependent on the slope (Figure 3a), and that $b_{0}$ increases strongly with discharge (Figure 6b,c), whereas $\alpha$ may depend on both $S$ and $Q$ (Figures 5 and 9). The limited dataset available does not enable us to explore this complicated behavior fully in order to develop a more generic formulation for the coefficient $k$.

In the relatively unconfined (TN1 and TN2) experiments (Figure 5), we observed that the scaled water discharge explains the observed variations of the curve shape as expressed through the coefficient $\alpha$. Interestingly, this result is consistent with Bertoldi et al. [2009a], which reveals that the parameters that describe the global complexity of the network (e.g. total braiding index) depend on the discharge, while indices related to the instantaneous morphological activity (e.g. active braiding index) are functions of stream power $\left(\Omega^{*}=\right.$ $\left.Q^{*} S\right)$. Nevertheless, for the experiment with relatively large $Q^{*}$, we cannot exclude a significant impact from the flume banks, which limit $W^{*}$ and the maximum width of the network. For this reason we interpret the lowest $\alpha$ in Figure 5 as a consequence of channel confinement, rather than a reaction to variations of water discharge or flume gradient. This is not the case for runs with $S \geq 0.7 \%$ where the belt width (defined as 
the area subject to morphological processes) is significantly smaller than the flume width (for instance $<2 \mathrm{~m}$ in run 10, Bertoldi et al. [2009a]).

\subsection{Effect of lateral confinement}

The impact of channel confinement on the braided morphology is consistent in both laboratory-scale and natural networks, as illustrated by the relationship between the exponent $\alpha$ (reflecting the shape of $b(D))$ and the unit discharge (Figure 9). In this analysis it is important to distinguish between two type of regimes: the first one occurs for $Q^{*} / W^{*}$ lower than $\sim 100$ and corresponds to fully developed and relatively unconfined braided networks (which show a coefficient $\alpha \geq 2$ ). The second reflects higher unit discharges and is dependent on the reduction of available width, which leads to a simpler morphology. It is noteworthy that the field-scale results shown in Figure 9b depend on the representative formative discharge, which affects the point position along the horizontal axis. Nevertheless, the qualitative result, i.e., the inverse correlation between unit discharge and the exponent $\alpha$, is relatively insensitive to discharge.

The relationship shown in Figure 9 can also be used to determine the point at which confinement becomes relevant in terms of channel morphology. However, it should be underlined that for unconfined networks which, by definition, do not depend on $W^{*}$, the unit discharge $Q^{*} / W^{*}$ is not the parameter that controls $\alpha$. By contrast, the alignment of the points in the left region of Figure 9 occurs probably because no runs with different $W^{*}$ are available for TN1 and TN2 experiments.

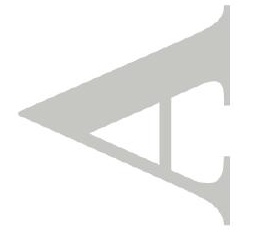




\subsection{Effect of riparian vegetation}

Neglecting the role of the vegetation is a reasonable assumption when examining the response of the Rees and the Sunwapta but less so for the Tagliamento. In this system, the mutual interaction between vegetation and river dynamics has been shown to significantly affect the braided morphology [Bertoldi et al., 2011]. Despite that, Figure 9b shows that the dependence of $\alpha$ on the unit discharge $Q^{*} / W^{*}$ in the Tagliamento is similar to that observed in the flume experiments. Such similarity does not imply that the vegetation does not affect the $b(D)$ curve; indeed the lower values of $\alpha$ are found for sub-reaches from 6 to 12 (corresponding to areas 10 to 21 in [Bertoldi et al., 2011]), where the vegetation is denser and the canopy is higher. To some extent the presence of vegetation seems to mimic the effect of channel confinement, so that it might impact the $b(D)$ curve through variations of the width $W^{*}$ with a similar $\alpha=f\left(Q^{*} / W^{*}\right)$ relation. However, the vegetation can also enhance fine sediment deposition, inducing further accretion of the higher areas, and therefore modifying the cross section shape.

\subsection{Controls on bed load flux}

The reach-averaged cross section embeds the information on the bed shear stress distribution, and can therefore be extended to predict bed load transport for complex morphologies [e.g. Bertoldi et al., 2009b].

This effect has previously been quantified by Nicholas [2000] who linked cross section morphology to the parameters of the Euler stress distribution [see also Paola, 1996]. However, the parameters of this distribution are dependent on the water discharge and for this reason Bertoldi et al. [2009b] attempted to relax the assumptions underpinning this approach, by modeling bed load flux based on the stress distribution predicted assuming uniform 
flow across complex topography, which does not require fitting to a probability density function.

Such existing methods are all based on the assumption that the cross section geometry is representative of the shear stress distribution. Here we tested this hypothesis by comparing the shear stress distribution obtained from the bed elevation distribution and the locally uniform flow assumption, with the shear stress distribution resulting from the spatially-explicit numerical modeling (Figure 10a). Results confirm the validity of this hypothesis when averaging at the reach-scale. Therefore, the proposed $b(D)$ curve can be taken as representative of the stress distribution, while the $\alpha$ exponent incorporates parsimoniously the key hydromorphological information needed to provide reach-scale estimates of wetted width and the bed load transport (Figures 10b and 11).

The present analysis does not account for the bed material sorting but considers a single, representative grain size. However, the formulation could be readily extended to a multi-grain bed load model [e.g. Parker, 1990], keeping the uniform flow assumption but considering a different Shields stress for the different sediment fractions. Moreover, our model could account for the spatial variability of the median grain size (i.e. patchiness) both as a random distribution or as a function of the bed elevation [Ferguson, 2003]. This would quantify the effect of bed coarsening at high stress zones, which is likely to reduce the Shields stress distribution in braided rivers with poorly sorted sediment [Seal and Paola, 1995].

\subsection{Controls on at-a-station variability}

Bertoldi et al. [2009b] suggested that the at-a-station variability is similar to the response in formative conditions. An explanation of this behavior stems from the character 
of the average section of Figure 3, which does not depend strongly on the water discharge. For this reason moving within a single curve gives a similar response, in terms of width and bed load, than moving between different curves. This is not the case for the confined network for which a variation of the discharge produces a significant modification of the average section. Consequently we should expect the at-a-station and formative response to be different than in the unconfined case. This reflects the well-known [e.g. Mosley, 1982; Ashmore, 2013] feature of braided rivers, whose water depth increases much slowly with the discharge than in a single-thread channel. Such behaviour is visible in equation (13), where the exponent of $D$ in a Y-shaped section is significantly greater than the typical $5 / 3$ value we can find in U-shaped channels.

A wide range of values for the exponent $\varphi$ of the width-discharge relationship (14) have been estimated for braided rivers; for example Mosley [1983] and Smith et al. [1996] reported low values $(\varphi<0.5)$, whereas Ashmore and Sauks [2006] obtained a nearly linear ( $\varphi \simeq 1)$ relation. Indeed, as highlighted by Ashmore and Sauks [2006], it is unlikely that there is a universal, generally applicable, width-discharge relationship for braided rivers. Smith et al. [1996] corroborated this hyphothesis, finding substantially different widthdischarge relations that could be ascribed mainly to differences in channel pattern.

The model we propose here states simply that $\varphi$ depends on the network complexity, ranging from values close to zero for nearly-rectangular sections to quasi-linear values for networks with large $\alpha$. This result is also useful to explain why complex networks show a more linear variations of bed load flux with driving discharge (Figure 12c). Indeed, in a braided system, a significant part variation in water discharge is accommodated by an increase in width (inundation of subaerial bars) and only partially by changes to 
the distribution of depth (i.e. Shields stress). Considering the strong non-linearity of the transport rate in response to stress variations [e.g. Parker, 1990], it is clear that the width adjustment leads to a more linear $Q s(Q)$ relation than for simpler (lower $\alpha$ ) topographies. For example, in the limiting case $\varphi \simeq 1$ the entire discharge variation is absorbed by the increase of width $b$, so that stress and unit transport are nearly constant, and the total bed load flux linearly responds to $Q$. This result is consistent with the well-known property of braided rivers to be morphologically active even during flow events of relatively small magnitude [e.g. Surian et al., 2009; Bertoldi et al., 2010].

The different response of braided and single-thread channels to flow variations is also evident when we analyze the at-a-station variability of the aspect ratio $\beta$. This is a key parameter in river morphodynamics, as it controls the amplitude of steady and migrating bars, and sets thresholds between different morphological regimes, from flat bed to alternate bars and from alternate bars to multiple bars [e.g Colombini et al., 1987; Crosato and Mosselmann, 2009]. Figure 12b reveals that in U-shaped channels the aspect ratio drops as the discharge increases, thus causing a reduction of bar height at peak flows [e.g. Tubino, 1991], while the opposite behaviour occurs in Y-shaped channels. This provides a conceptual framework to interpret the diverse morphological changes driven by changes in discharge, such as the increase of braiding index with the flow discharge observed by Egozi and Ashmore [2009] and the tendency of braided rivers to form more complex networks after large floods [Marra et al., 2014].

\section{Conclusions}

In this paper we have described a new elevation-based distribution function approach to quantifying the complexity, and explaining the dynamical response of braided rivers to 
external controls at the reach-scale.

Through the analysis of 58 flume experiments alongside data from three natural gravel bed rivers, we found that the shape of the reach-average section can be conveniently represented by the exponent $(\alpha)$ of a power law fitting the cumulative elevation distribution function. This exponent is strongly correlated with the formative controls, in particular discharge and valley slope, and is highly sensitive to lateral confinement. Specifically, $\alpha$ varies in between $1.5-2.5$ for braided rivers (and a so-called Y-shaped average section) to $\alpha<1$ with a characteristically of U-shaped cumulative distribution function associated with single-thread channels as the unit flow discharge increases. As a result, the method provides a reach-scale index that can be used as a diagnostic tool to quantify changes in the morphological trajectory of braided rivers driven by anthropogenic and natural forcing. Moreover, this reach-scale index can also be used to calibrate and test physical and numerical models by assessing their capability to reproduce geomorphic characteristics of prototype braided rivers.

Comparison with spatially-explicit numerical hydrodynamic simulations and laboratory experiments indicates that the proposed average channel formulation, implemented under the assumption of locally uniform flow, is able to capture the reach-scale morphological complexity of braided rivers and provides robust estimates of bed shear stress and bed load flux. This enables ready computation of the at-a-station response of braided channels to changing discharge, and reveals that relatively high exponents $\alpha$ lead to a large variation of the wetted width and consequently to a smoother response of the transport rate.

The present analysis is limited to braided rivers with relatively coarse material and high 
valley slope. However, the indicator we introduced could be readily applied to a wider range of fluvial environments (e.g. sand-bed braided rivers), for which different responses to the key controlling factors might be identified.

\section{Acknowledgments.}

This work has been carried out within the SMART Joint Doctorate (Science for the MAnagement of Rivers and their Tidal systems) funded with the support of the Erasmus Mundus programme of the European Union. Data of the Rees River were derived as part of UK Natural Environment Research Council grant (NE/G005427/1) awarded to PI Brasington, along with further support from the NERC Geophysical Equipment Facility (Loan 892) and Leverhulme Trust IAF2014-038. Access to these data is available by contacting the author directly (j.brasington@qmul.ac.uk). Other flume and field data, as well as the Delft3D numerical setup are from cited references. The paper has highly benefited from the constructive comments of C. Paola, J. C. Schmidt and an anonymous reviewer.

\section{References}

Ashmore, P. (1982), Laboratory modeling of gravel braided-stream morphology, Earth Surface Processes and Landforms, 7, 201-225.

Ashmore, P. (1988), Bed load transport in braided gravel-bed stream models, Earth Surface Processes and Landforms, 13, 677-695.

Ashmore, P. (1991), Channel morphology and bed load pulses in braided, gravelbed streams, Geografiska Annaler. Series A, Physical Geography, 73(1), 37-52, doi: $10.2307 / 521212$ 
Ashmore, P. (2013), Morphology and dynamics of braided rivers, in Treatise on Geomorphology, vol. 9, Fluvial Geomorphology, edited by J. Shroder and E. Wohl, pp. 289-312, Academic Press, San Diego, CA, doi:10.1016/S1099-4831(10)06803-3.

Ashmore, P., and E. Sauks (2006), Prediction of discharge from water surface width in a braided river with implications for at-a-station hydraulic geometry, Water Resources Research, 42, 1-11, doi:10.1029/2005WR003993.

Ashmore, P., W. Bertoldi, and J. T. Gardner (2011), Active width of gravel-bed braided rivers, Earth Surface Processes and Landforms, 36, 1510-1521, doi:10.1002/esp.2182.

Barenblatt, G. I. (1996), Scaling, self-similarity, and intermediate asymptotics: dimensional analysis and intermediate asymptotics, vol. 14, Cambridge University Press.

Bertoldi, W., L. Zanoni, and M. Tubino (2009a), Planform dynamics of braided rivers, Earth Surface Processes and Landforms, 34, 547-557, doi:10.1002/esp.1755.

Bertoldi, W., P. Ashmore, and M. Tubino (2009b), A method for estimating the mean bed load flux in braided rivers, Geomorphology, 103, 330-340, doi: 10.1016/j.geomorph.2008.06.014.

Bertoldi, W., W. Zanoni, and M. Tubino (2010), Assessment of morphological changes induced by flow and flood pulses in a gravel bed braided river: The Tagliamento River (Italy), Geomorphology, 114, 348-360, doi:10.1016/j.geomorph.2009.07.017.

Bertoldi, W., N. A. Drake, and A. M. Gurnell (2011), Interactions between river flows and colonizing vegetation on a braided river: exploring spatial and temporal dynamics in riparian vegetation cover using satellite data, Earth Surface Processes and Landforms, 36, 1474-1486, doi:10.1002/esp.2166. 
Brasington, J. (2010), From grain to floodplain: Hyperscale models of braided rivers, Journal of Hydraulic Research, 45.

Brasington, J., D. Vericat, and I. Rychkov (2012), Modeling river bed morphology, roughness, and surface sedimentology using high resolution terrestrial laser scanning, Water Resources Research, 48, doi:10.1029/2012WR012223.

Carson, M. A., and G. A. Griffith (1987), Bedload transport gravel channels, Journal of Hydrology, 151.

Colombini, M., G. Seminara, and M. Tubino (1987), Finite amplitude alternate bars, Journal of Fluid Mechanics, 181, 213-232.

Coulthard, T. (2005), Effects of vegetation on braided stream pattern and dynamics, Water Resources Research, 41, doi:10.1029/2004WR003201.

Crosato, A., and E. Mosselmann (2009), Simple physics-based predictor for the number of river bars and the transition between meandering and braiding, Water Resources Research, 45, doi:10.1029/2008WR007242.

Davies, T. R. H. (1987), Problems of bedload transport in braided gravel-bed rivers, in Sediment Transport in Gravel-Bed Rivers, edited by C. R. Thorne, J. S. Bathurst, and R. D. Hey, pp. 793-811, Wiley, Chichester.

Egozi, R., and P. Ashmore (2008), Defining and measuring braiding intensity, Earth Surface Processes and Landforms, 33, 2121-2138, doi:10.1002/esp.1658.

Egozi, R., and P. Ashmore (2009), Experimental analysis of braided channel pattern response to increased discharge, Journal of Geophysical Research: Earth Surface, 114(2), 1-15, doi:10.1029/2008JF001099. 
Einstein, H. A. (1950), The Bed-load Function for Sediment Transportation in Open Channel Flow, Technical bulletin No. 1026.

Engelund, F., and J. Fredsoe (1982), Sediment ripples and dunes, Annual Review of Fluid Mechanics, 14, 13-37.

Ferguson, R. I. (2003), The missing dimension: effects of lateral variation on 1-D calculations of fluvial bedload transport, Geomorphology, 56, 1-14, doi:10.1016/S0169$555 \mathrm{X}(03) 00042-4$

Gao, J. (2009), Bathymetric mapping by means of remote sensing: methods, accuracy and limitations, Progress in Physical Geography, 33, 103-116, doi: $10.1177 / 0309133309105657$.

Garcia Lugo, G. A., W. Bertoldi, A. J. Henshaw, and A. M. Gurnell (2015), The effect of lateral confinement on gravel bed river morphology, Water Resources Research, 51(9), 7145-7158, doi:10.1002/2015WR017081.

Glover, R. E., and Q. L. Florey (1951), Stable channel profiles, United States Bureau of Reclamation, Denver, Colorado, Report Hyd-325.

Gran, K., and C. Paola (2001), Riparian vegetation controls on braided stream dynamics, Water Resources Research, 37(12), 3275-3283, doi:10.1029/2000WR000203.

Griffith, G. A. (1989), Conversion of braided gravel-bed rivers to single-thread channels of equivalent transport capacity, Journal of Hydrology New Zealand, 28, 63-75.

Gurnell, A. M., G. E. Petts, D. M. Hannah, B. P. G. Smith, P. J. Edwards, J. Kollmann, J. V. Ward, and K. Tockner (2001), Riparian vegetation and island formation along the gravel-bed Fiume Tagliamento, Italy, Earth Surface Processes and Landforms, 26, $31-62$. 
Hoey, T. B., and A. Sutherland (1991), Channel morphology and bedload pulses in a braided river, Earth Surface Processes and landforms, 16, 447-462.

Hundey, E. J., and P. E. Ashmore (2009), Length scale of braided river morphology, Water Resources Research, 45(8), 501-516, doi:10.1029/2008WR007521.

Liebault, F., S. Lallias-Tacon, M. Cassel, and N. Talaska (2012), Long profile responses of alpine braided rivers in SE France, River Research and Applications, 29(10), 1253-1266, doi:10.1002/rra.2615.

Marcus, W. A., and M. A. Fonstad (2010), Remote sensing of rivers: The emergence of a subdiscipline in the river sciences, Earth Surface Processes and Landforms, 35, 1867-1872, doi:10.1002/esp.2094.

Marra, W. A., M. G. Kleinhans, and E. A. Addink (2014), Network concepts to describe channel importance and change in multichannel systems: test results for the Jamuna River, Bangladesh, Earth Surface Processes and Landforms, 39, 766-778, doi: 10.1002/esp.3482.

Martín-Vide, J., A. Plana-Casado, A. Sambola, and S. Capapé (2015), Bedload transport in a river confluence, Geomorphology, 250, 15-28, doi:10.1016/j.geomorph.2015.07.050. Meyer-Peter, E., and R. Müller (1948), Formulas for bed load transport, Proceedings of the 2nd IAHR Congress, 2, 39-64.

Mosley, M. P. (1982), Analysis of the effect of changing discharge on channel morphology and instream uses in a braided river, Ohau River, New Zealand, Water Resources Research, 18(4), 800-812.

Mosley, M. P. (1983), Response of braided rivers to changing discharge, Journal of Hydrology New Zealand, 22, 18-67. 
Nicholas, A. P. (2000), Modeling bedload yield in braided gravel bed rivers, Geomorphology, 36, 89-106, doi:10.1016/S0169-555X(00)00050-7.

Nicholas, A. P., P. J. Ashworth, G. H. S. Smith, and S. D. Sandbach (2013), Numerical simulation of bar and island morphodynamics in anabranching megarivers, 118, 20192044, doi:10.1002/jgrf.20132.

Paola, C. (1996), Incoherent structure: turbulence as a metaphor for stream braiding, Coherent Flow Structures in Open Channels, 65, 705-723.

Paola, C., and E. Foufoula-Georgiou (2001), Statistcal geometry and dynamics of braided rivers, in Gravel bed rivers V, edited by M. P. Mosley, pp. 47-69, New Zealand Hydrologic Society, Christchurch.

Parker, G. (1990), Surface-based bedload transport relation for gravel rivers, Journal of Hydraulic Research, 28, 417-436.

Parker, G., P. R. Wilcock, C. Paola, W. E. Dietrich, and J. Pitlick (2007), Physical basis for quasi-universal relations describing bankfull hydraulic geometry of single-thread gravel bed rivers., Journal of Geophysical Research: Earth Surface, 112(4), 1-21, doi: 10.1029/2006JF000549.

Robertson-Rintoul, M. S. E., and K. S. Richards (1993), Braided-channel pattern and palaeohydrology using an index of total sinuosity., Geological Society, London, Special Publications, 75, 113-118, doi:10.1144/GSL.SP.1993.075.01.06.

Seal, R., and C. Paola (1995), Observations of downstream fining on the North Fork Toutle River near Mount St. Helens, Washington, Water Resources Research, 31(5), 1409-1419, doi:10.1029/94WR02976. 
Schuurman, F., W. A. Marra, and M. G. Kleinhans (2013), Physics-based modeling of large braided sand-bed rivers: Bar pattern formation, dynamics, and sensitivity, Journal of Geophysical Research: Earth Surface, 118(4), 2509-2527, doi:10.1002/2013JF002896.

Shvidchenko, A. B., and Z. D. Kopaliani (1998), Hydraulic Modeling of Bed Load transport in Gravel-Bed Laba River, Journal of Hydrology, 124, doi:10.1061/(ASCE)07339429(1998)124:8(778).

Smith, L. C., B. Isacks, and A. Bloom (1996), Estimation of discharge from three braided rivers using synthetic aperture radar satellite imagery: Potential application to ungauged basins, Water Resources Research, 32(7), 2021-2034, doi:10.1029/96WR00752.

Surian, N. (1999), Channel changes due to river regulation: the case of the Piave River, Italy, Earth Surface Processes and Landforms, 24, 1135-1151.

Surian, N., L. Ziliani, F. Comiti, M. A. Lenzi, and L. Mao (2009), Channel adjustment and alteration of sediment fluxes in gravel-bed rivers of the North-Eastern Italy: potential and limitations for channel recovery, River Research and Applications, 25, 551-567, doi:10.1002/rra.1231.

Thompson, A. (1985), Transport of gravel by flows up to $500 \mathrm{~m}^{3} \mathrm{~s}^{-1}$, Ohau River, Otago, New Zealand, Journal of Hydraulic Engineering, 23, 285-303, doi: $10.1080 / 00221688509499356$.

Tockner, K., J. Ward, D. Arscott, P. Edwards, J. Kollmann, A. Gurnell, G. Petts, and B. Maiolini (2003), The Tagliamento River: a model ecosystem of European importance, Aquatic Sciences, 65(3), 239-253, doi:10.1007/s00027-003-0699-9.

Toffolon, M., and A. Crosato (2007), Developing Macroscale Indicators for Estuarine Morphology: The Case of the Scheldt Estuary, Journal of Coastal Research, 23(1), 
195-212, doi:10.2112/03-0133.1.

Tubino, M. (1991), Growth of alternate bars in unsteady flow, Water Resources Research, $27(1), 37-52$.

van der Nat, D., A. P. Schmidt, K. Tockner, E. P. J., and J. V. Ward (2002), Inudation dynamics in braided floodplains: Tagliamento River, Northeast Italy, Ecosystems, 5, 636-647, doi:10.1007/s10021-002-0170-0.

van Dijk, W. M., R. Teske, W. I. Van de Lageweg, and M. G. Kleinhans (2013), Effects of vegetation distribution on experimental river channel dynamics, Water Resources Research, 49(11), 7558-7574, doi:10.1002/2013WR013574.

Welber, M., W. Bertoldi, and M. Tubino (2012), The response of braided planform configuration to flow variations, bed reworking and vegetation: the case of the Tagliamento River, Italy, Earth Surface Processes and Landforms, 37, 572-582, doi:10.1002/esp.3196.

Wheaton, J. M., J. Brasington, S. E. Darby, and D. A. Sear (2010), Accounting for uncertainty in DEMs from repeat topographic surveys: improved sediment budgets, Earth Surface Processes and Landforms, 35, 136-156, doi:10.1002/esp.1886.

Welber, M., W. Bertoldi, and M. Tubino (2013), Wood dispersal in braided streams: Results from physical modeling, Water Resources Research, 49, 7388-7400, doi: 10.1002/2013WR014046.

Willgoose, G., and G. Hancock (1998), Revisiting the hypsometric curve as an indicator of form and process in transport-limited catchment, Earth Surface Processes and Landforms, 23, 611-623, doi:10.1002/(SICI)1096-9837(199807)23:7;611::AIDESP872;3.0.CO;2-Y. 
Williams, R. D., J. Brasington, M. Hicks, C. D. Rennie, and D. Vericat (2013), Hydraulic validation of two-dimensional simulations of braided river flow with spatially continuous aDcp data, Water Resources Research, 49(9), 5183-5205, doi:10.1002/wrcr.20391.

Williams, R. D., J. Brasington, D. Vericat, and D. M. Hicks (2014), Hyperscale terrain modelling of braided rivers: fusing mobile terrestrial laser scanning and optical bathymetric mapping, Earth Surface Processes and Landforms, 39(2), 167-183, doi: $10.1002 / \operatorname{esp} .3437$.

Williams, R. D., J. Brasington, and D. M. Hicks (2016), Numerical modelling of braided river morphodynamics: review and future challenges, Geography Compass, $10(3), 102-$ 127, doi:10.1111/gec3.12260.

Wong, M., and G. Parker (2006), Reanalysis and correction of bed-load relation of MeyerPeter and Müller using their own database., Journal of Hydraulic Engineering, 132(11), 1159-1168, doi:10.1061/(ASCE)0733-9429(2006)132:11(1159).

Young, W. J., and T. R. H. Davies (1990), Prediction of bedload transport rates in braided rivers: A hydraulic model study, Journal of Hydrology, 29.

Young, W. J., and T. R. H. Davies (1991), Bed load transport processes in a braided gravel-bed, Earth Surface Processes and Landforms, 16, 499-511.

Young, W. J., and W. Warburton (1996), Principles and practice of hydraulic modelling of braided gravel-bed rivers, Journal of Hydrology, 35, 175-198. 


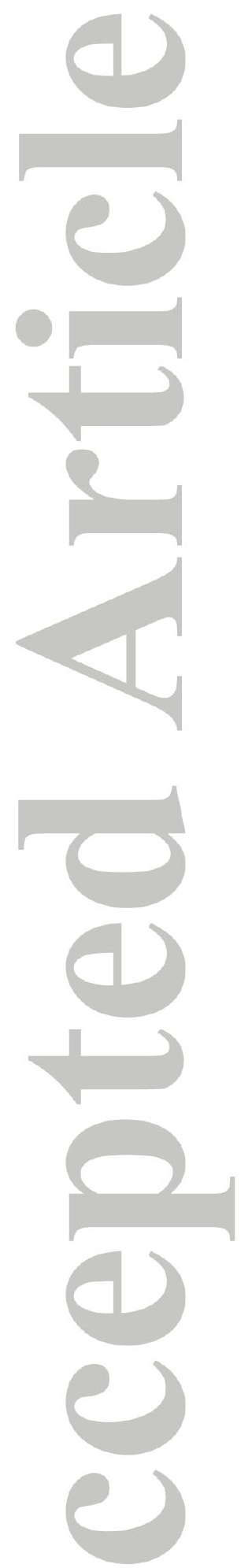

Figure 1. (a) Example of a single cross section with the definition of the width $b_{x}$ as a function of the elevation $D$ with respect to the lowest point; and (b) example of the reach-averaged $b(D)$ curve, obtained by integrating $b_{x}$ along a reach of length $L$. The dashed line is the power law approximation of equation (2); $\eta$ and $h$ indicate bed elevation and flow depth along the transverse direction $(y)$. 


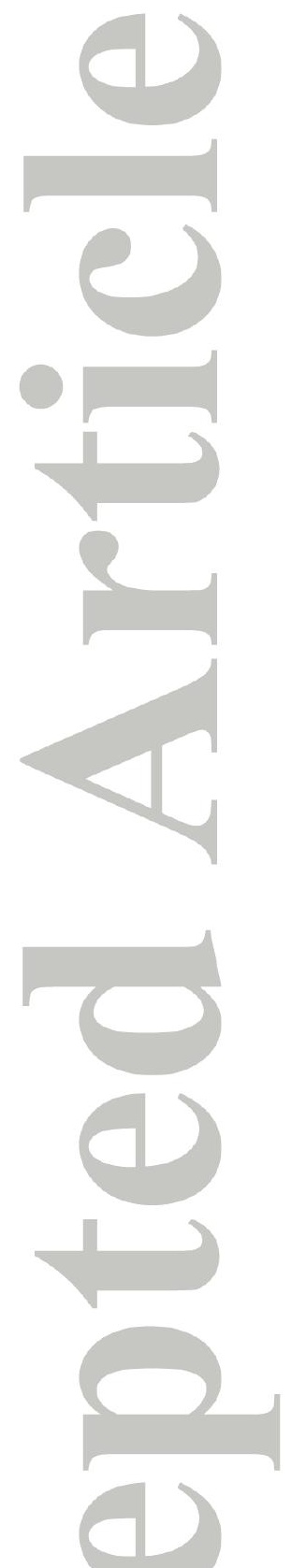

Figure 2. Three characteristic cross section types (left) and corresponding reach-scale $b(D)$ curve (center) and average section (right): (a) concave upward shape; (b) triangular shape; (c) concave downward shape, with $\alpha$ indicating the exponent of the power law (2).

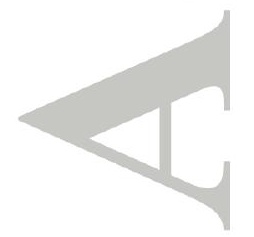

D R A F T

May $13,2016,11: 37 a m$

D R A F T 


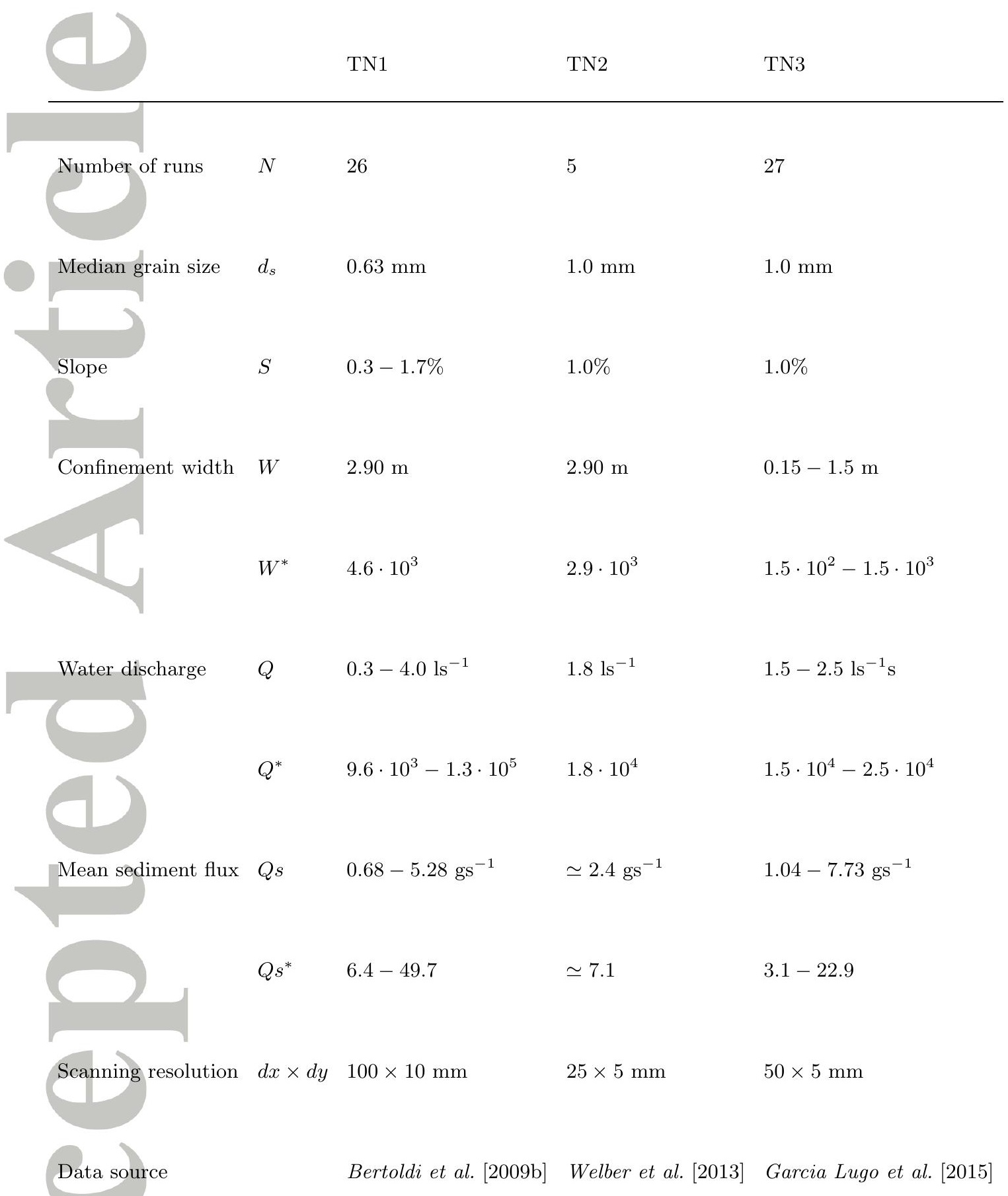

Table 1. Summary of the main features of the laboratory experiments. The star superscript indicates dimensionless variables.

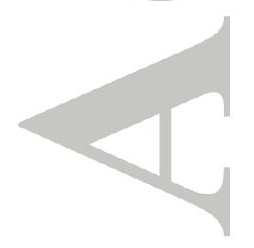




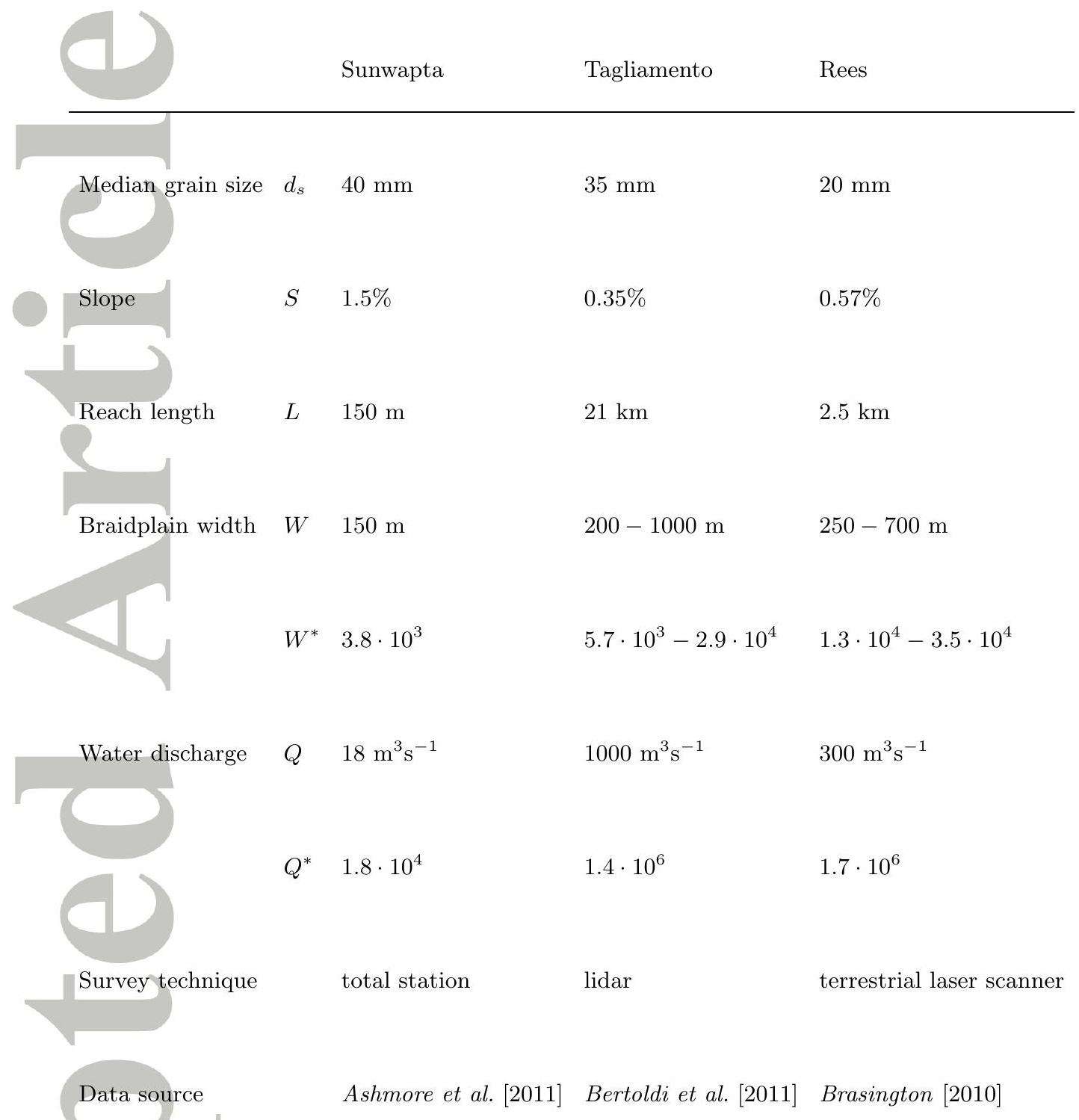

Table 2. Summary of the representative parameters used for the three rivers. The star superscript indicates dimensionless variables. 


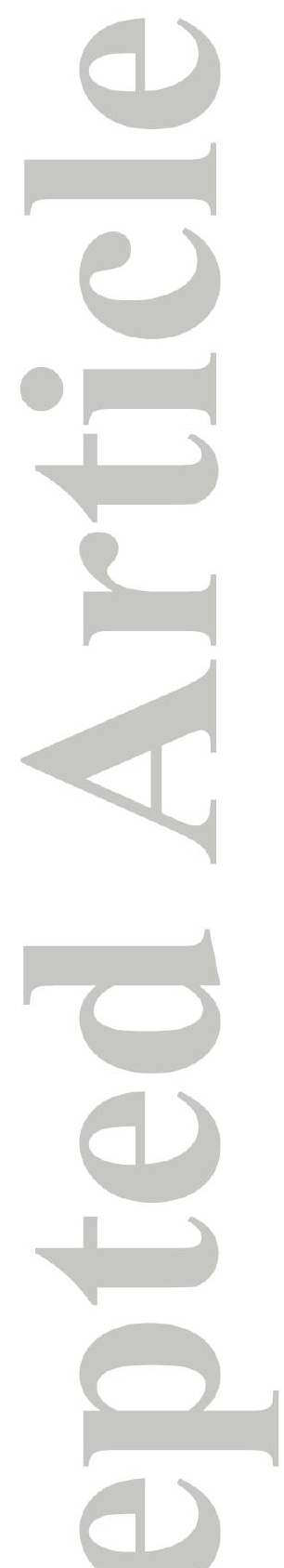

Figure 3. Reach-averaged width-depth curves (in scaled variables) for the TN1 and TN2 experiments (a), and for the Sunwapta River (b).

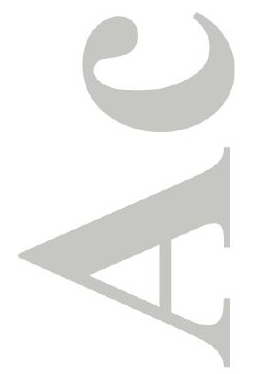




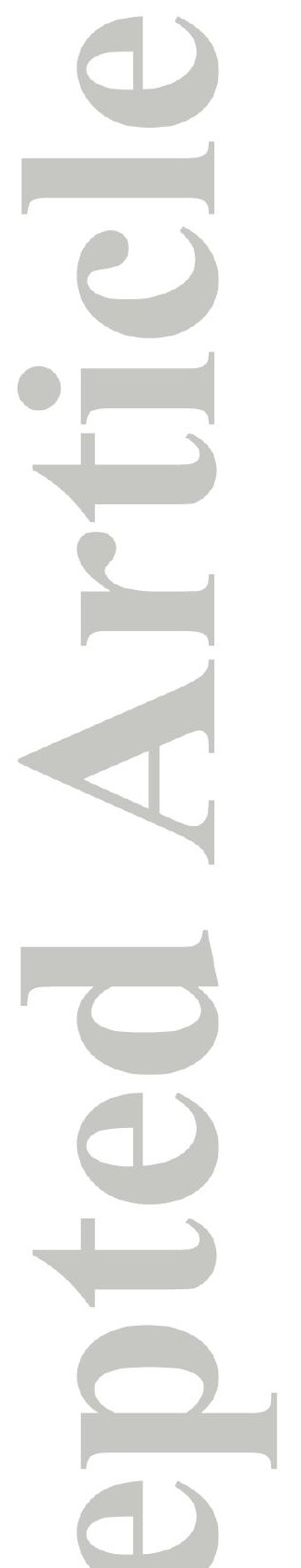

Figure 4. Reach-averaged, dimensionless bed relief index for TN1 and TN2 experiments and for the Sunwapta River.

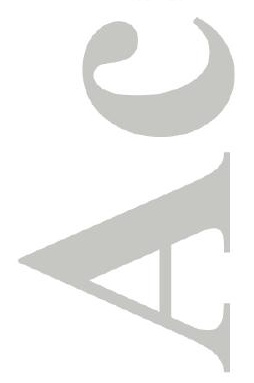

D R A F T

May 13, 2016, 11:37am

D R A F T 


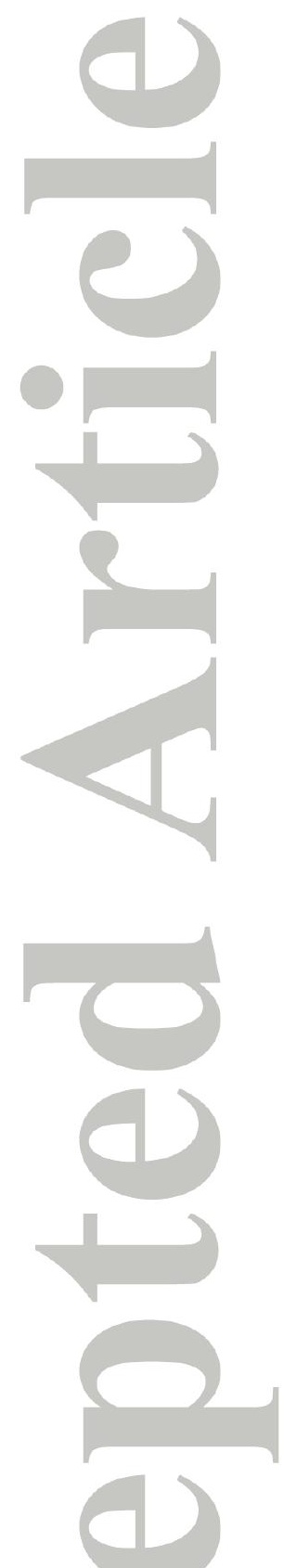

Figure 5. Coefficient of the best fitting power law $(\alpha)$ for the TN1, TN2, TN3 experiments, and the Sunwapta River against scaled discharge $Q^{*}$. The dashed line represents the linear fitting of TN1 and TN2 experiments.

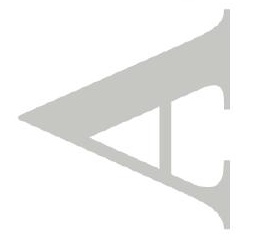

D R A F T

May 13, 2016, 11:37am

D R A F T 


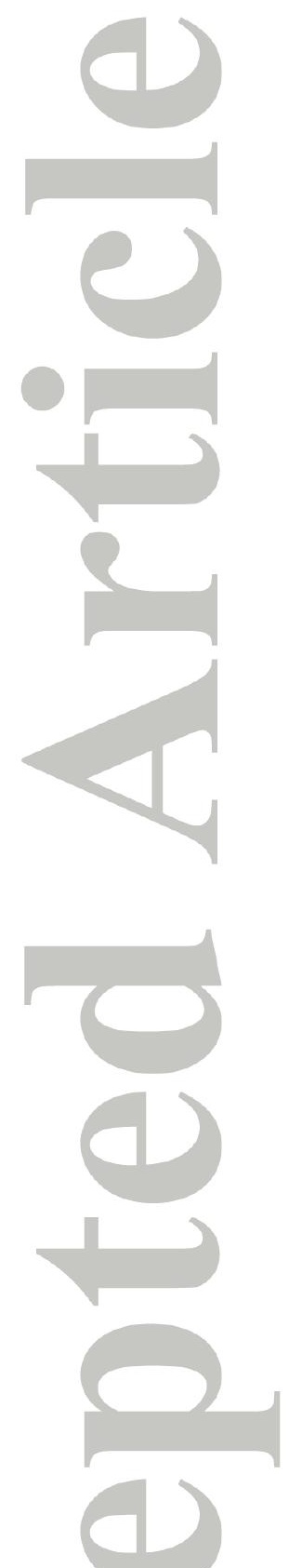

Figure 6. (a) Study area of the Tagliamento River and selected sub-reaches; the map is centered at $46^{\circ} 12^{\prime} N, 13^{\circ} 00^{\prime} \mathrm{E}$; the color map represents bed elevation in $[\mathrm{m}]$ relative to the local minimum elevation. (b) Reach-averaged width-depth curves for different sub-reaches of the Tagliamento, and (c) for the Rees River. The end markers of each curve indicate the formative conditions as defined by the simple uniform flow model. 


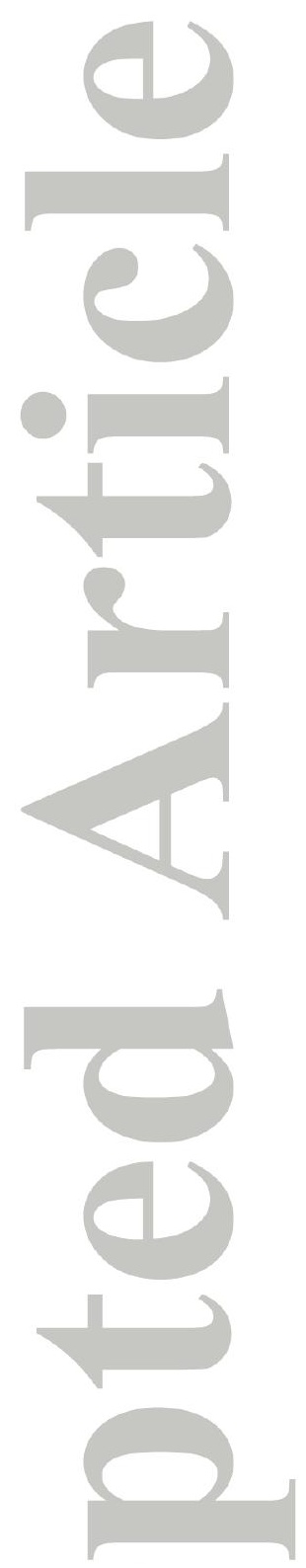

Figure 7. Coefficient of determination for the power law approximation, equation (2), of the width-depth curves. Results for the 72 reaches of the laboratory and field dataset are plotted against the best fitting coefficient $\alpha$.

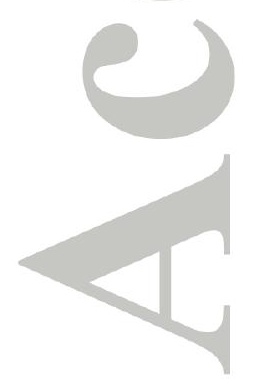

D R A F T

May 13, 2016, 11:37am

D R A F T 


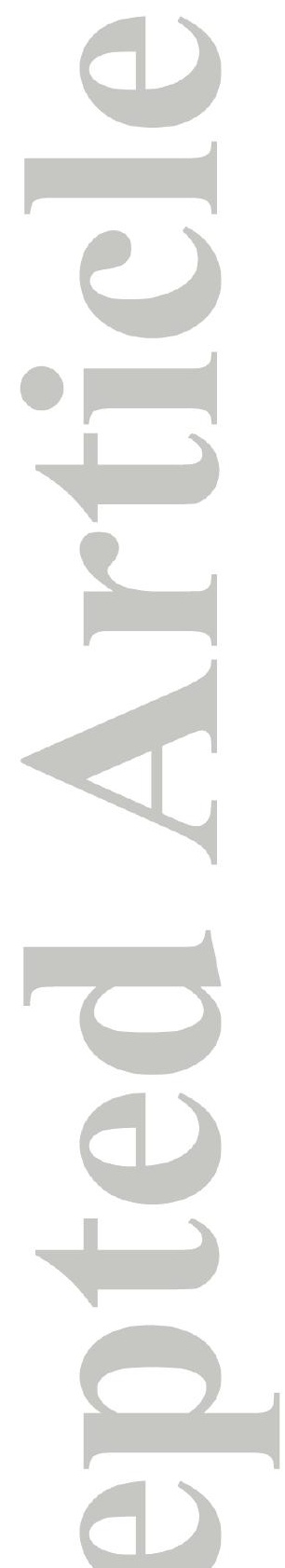

Figure 8. Reach-averaged width-depth curves of the TN3 experiments with $Q=2.0 \mathrm{ls}^{-1}$ for different dimensionless confinement width $W^{*}$. The end markers of each curve indicate the formative conditions as defined by the simple uniform flow model.

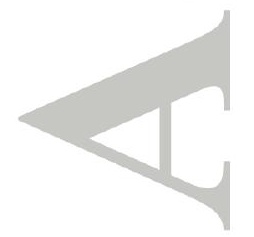

D R A F T

May $13,2016,11: 37 a m$

D R A F T 


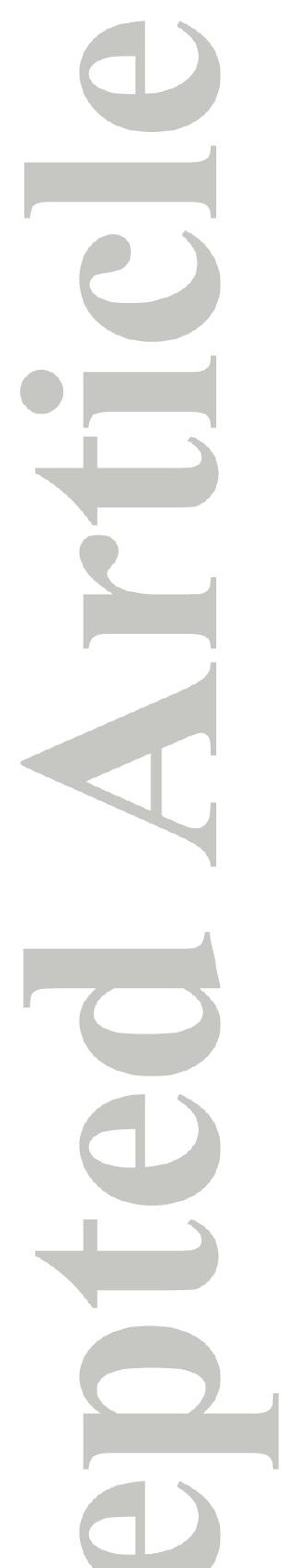

Figure 9. Exponent of the best fitting power law as a function of the dimensionless flow discharge per unit width. (a) TN1, TN2, TN3 experiments. (b) Sunwapta River and sub-reaches of the Tagliamento River.

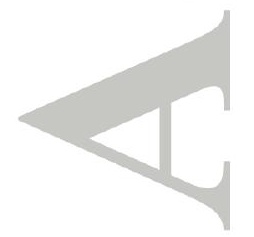

D R A F T

May 13, 2016, 11:37am

D R A F T 


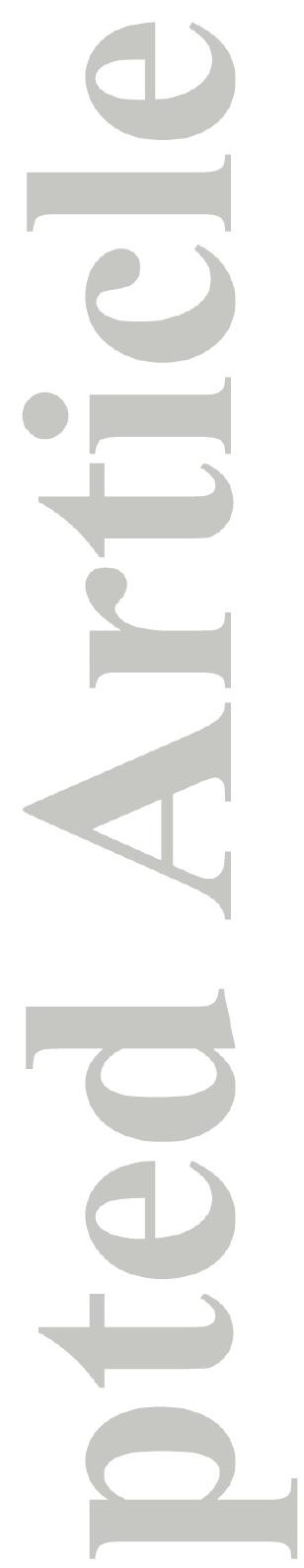

Figure 10. Comparison between the 2D numerical simulation (continuous lines) and the average section method (dashed lines) for the Rees River. (a) Cumulative Shields stress distributions with discharge $Q=323 \mathrm{~m}^{3} \mathrm{~s}^{-1}$ and $Q=200 \mathrm{~m}^{3} \mathrm{~s}^{-1}$, where $b^{*}$ indicates the area where the Shields stress exceeds a given value, scaled with the reach length. The vertical axis of panel (a) has been reversed to easily recognize the average section profile. (b) Reach-averaged wetted width and bed load as a function of the water discharge. 


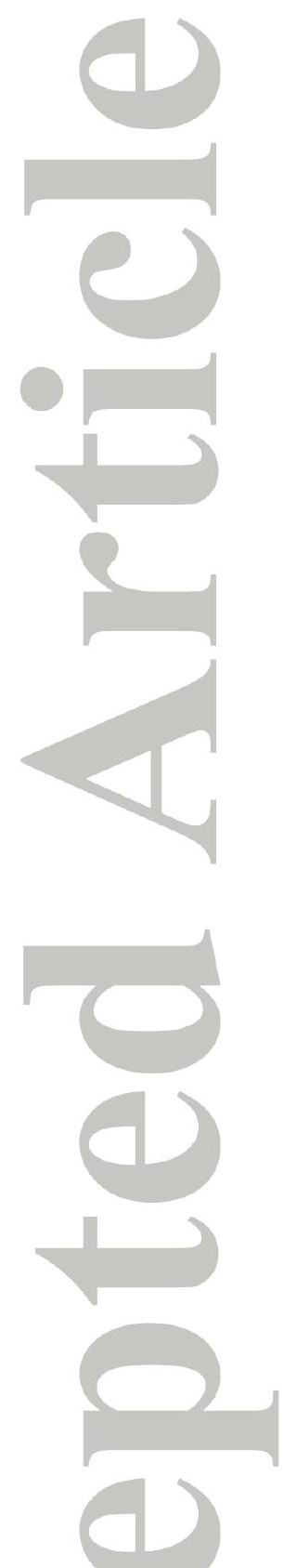

Figure 11. Measured bed load flux in the TN1 laboratory experiments compared with the estimates of Bertoldi et al. [2009b] (squares) and the average section method (circles). The Engelund and Fredsoe [1982] resistance formula and the Parker [1990] transport relation are used.

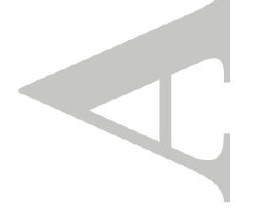




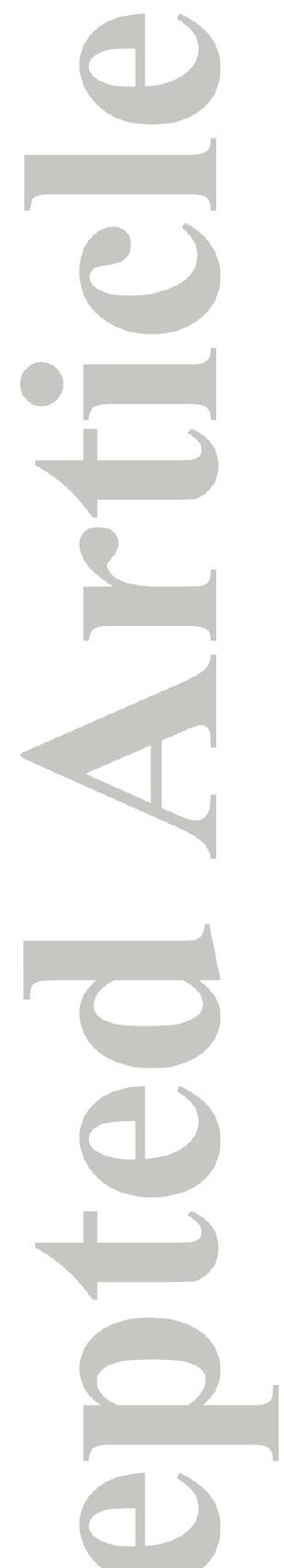

Figure 12. At-a-station variability of (a) wetted width, (b) width-to-depth ratio $(\beta=B / D)$, and (c) bed load flux for distinct values of the exponent $\alpha$ of the average section. Plots are normalized with respect to the formative conditions.

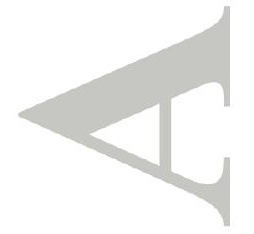

D R A F T

May $13,2016,11: 37 a m$

D R A F T 
(a) $\eta$

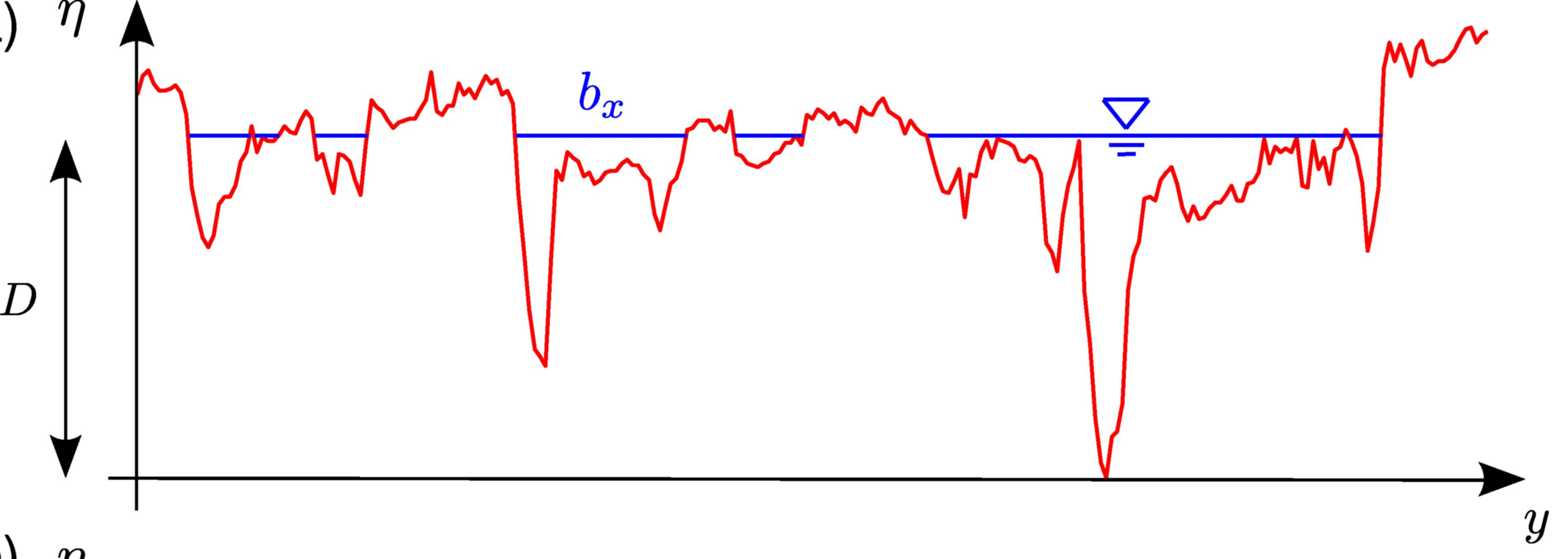

(b) $\eta$

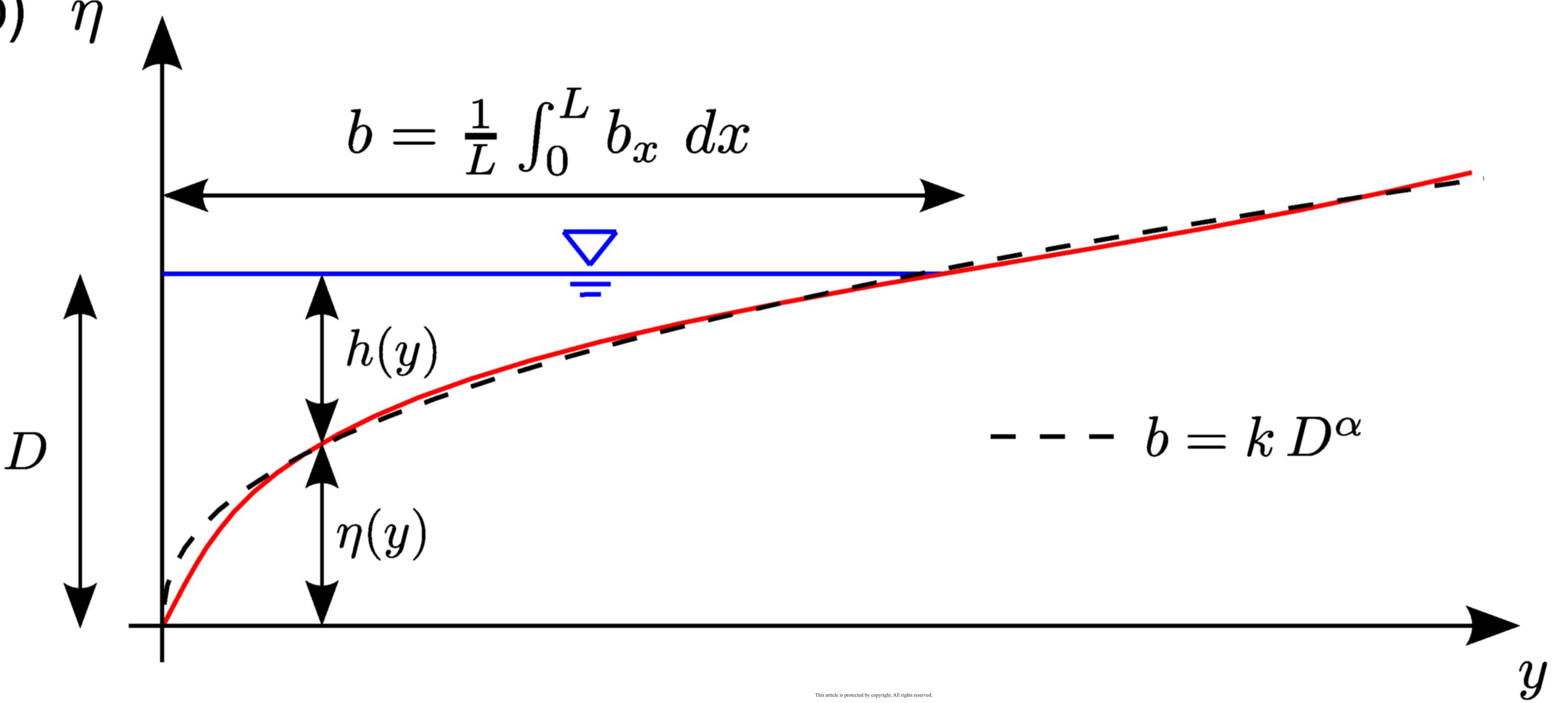



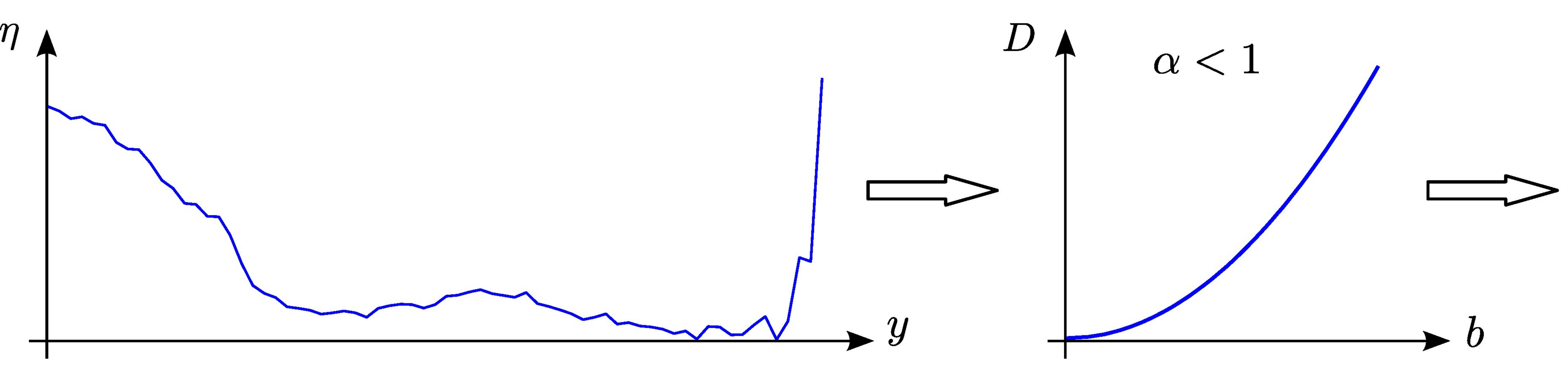

$U$-shaped section

(b)
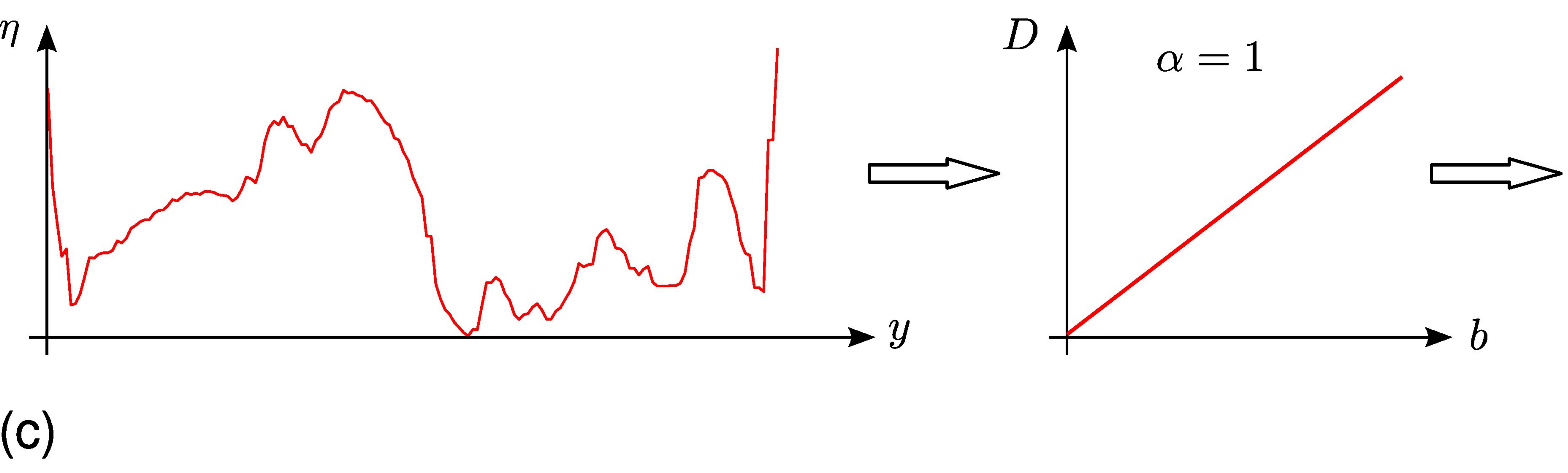

$V$-shaped section

(c)
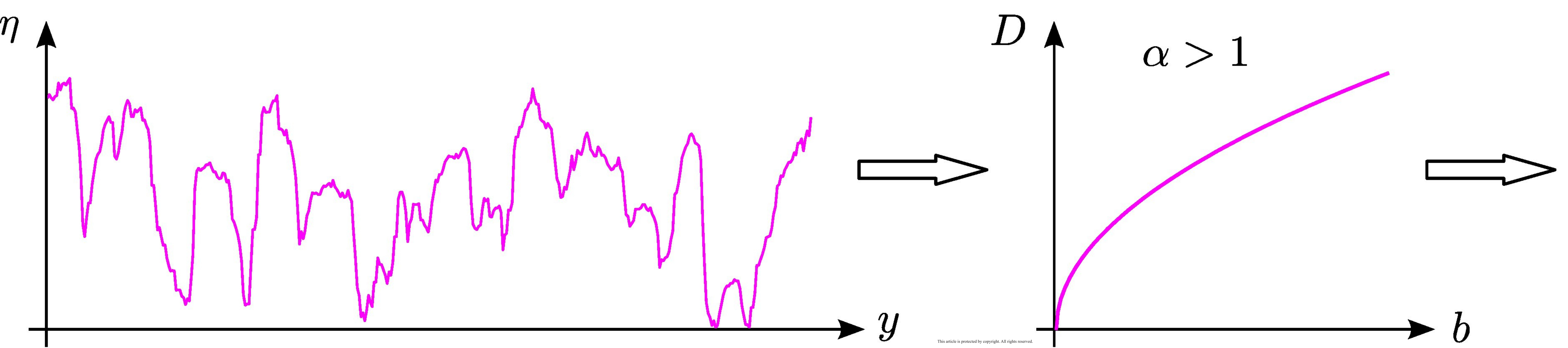

Y-shaped section

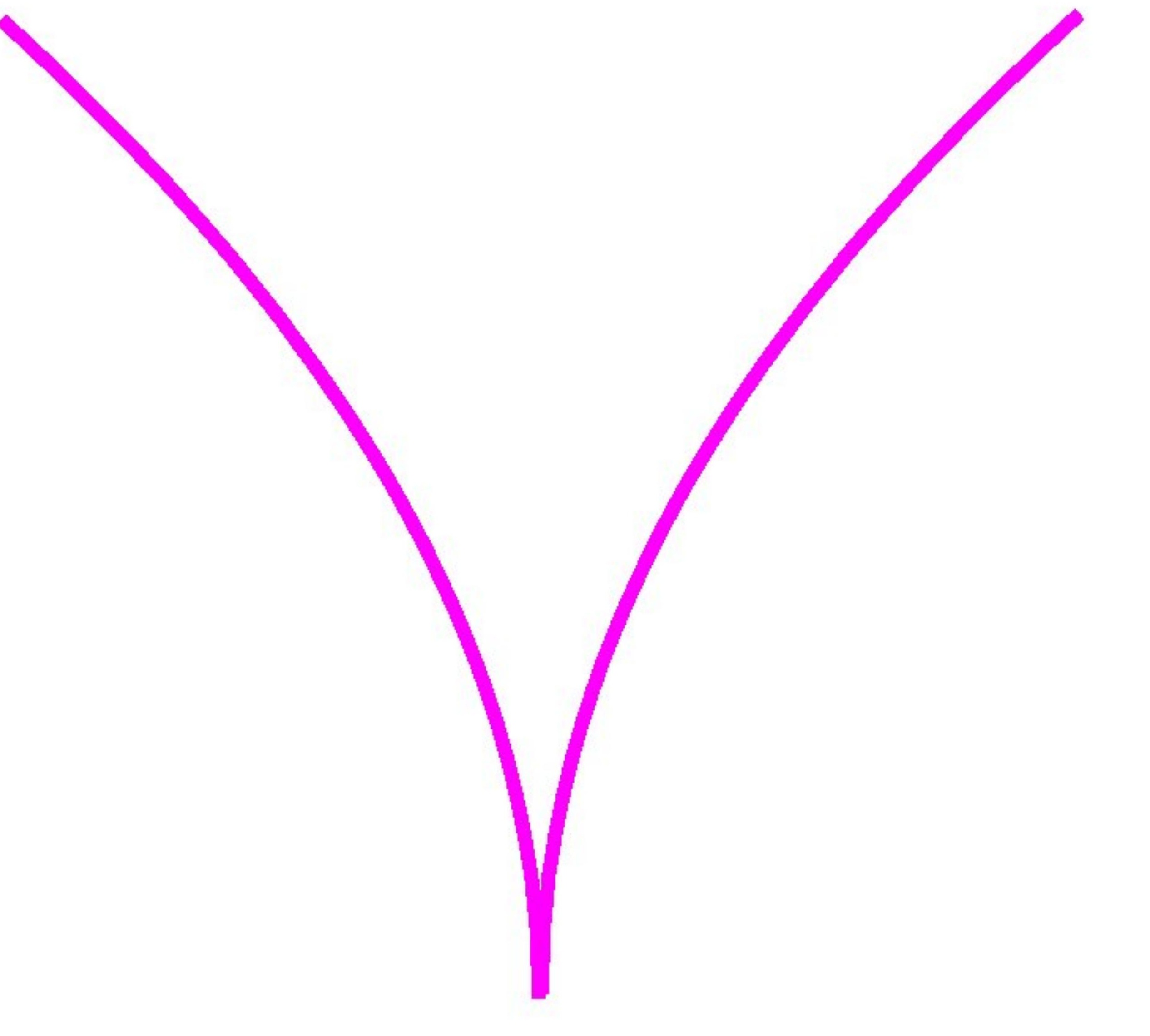




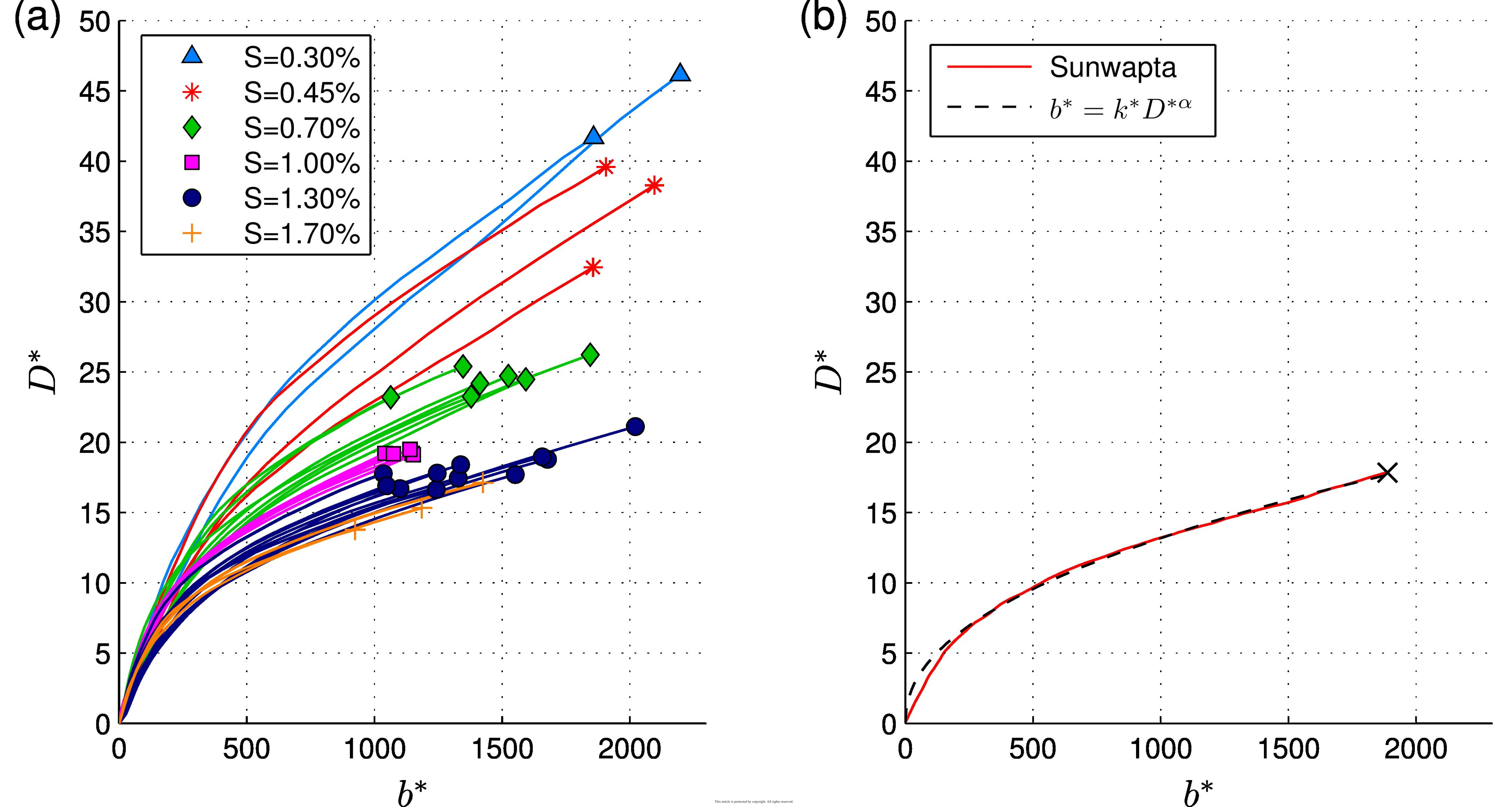




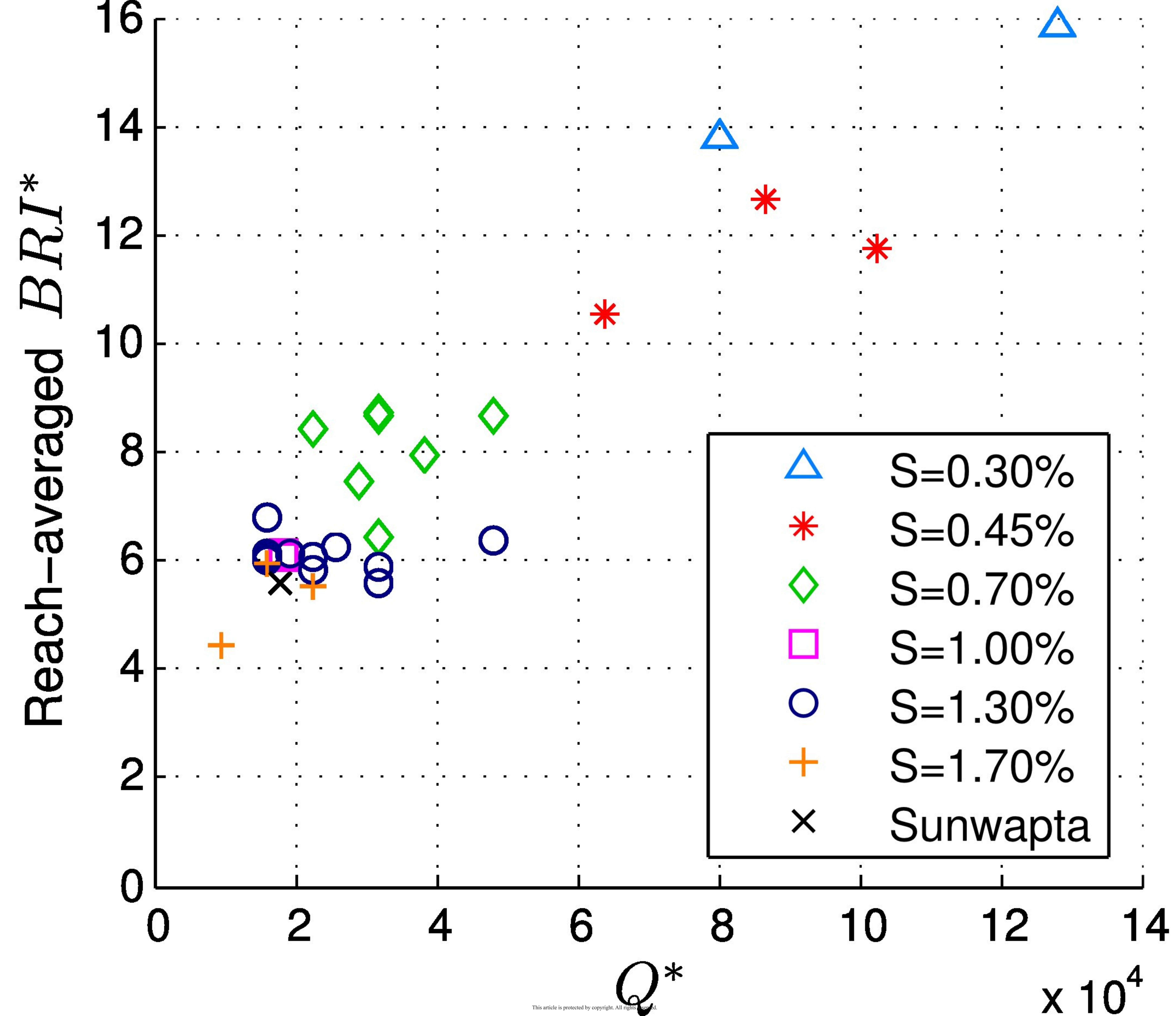




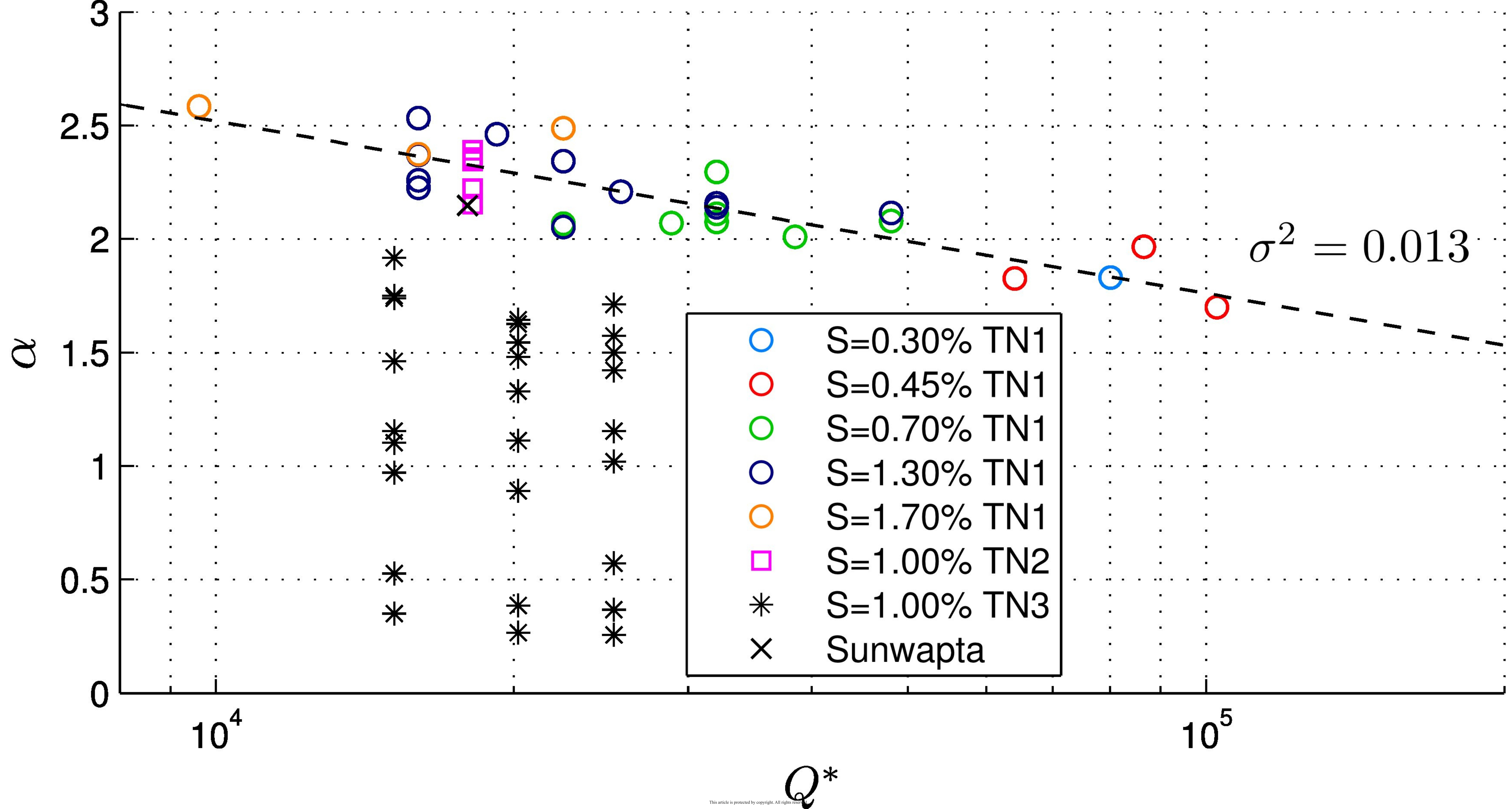




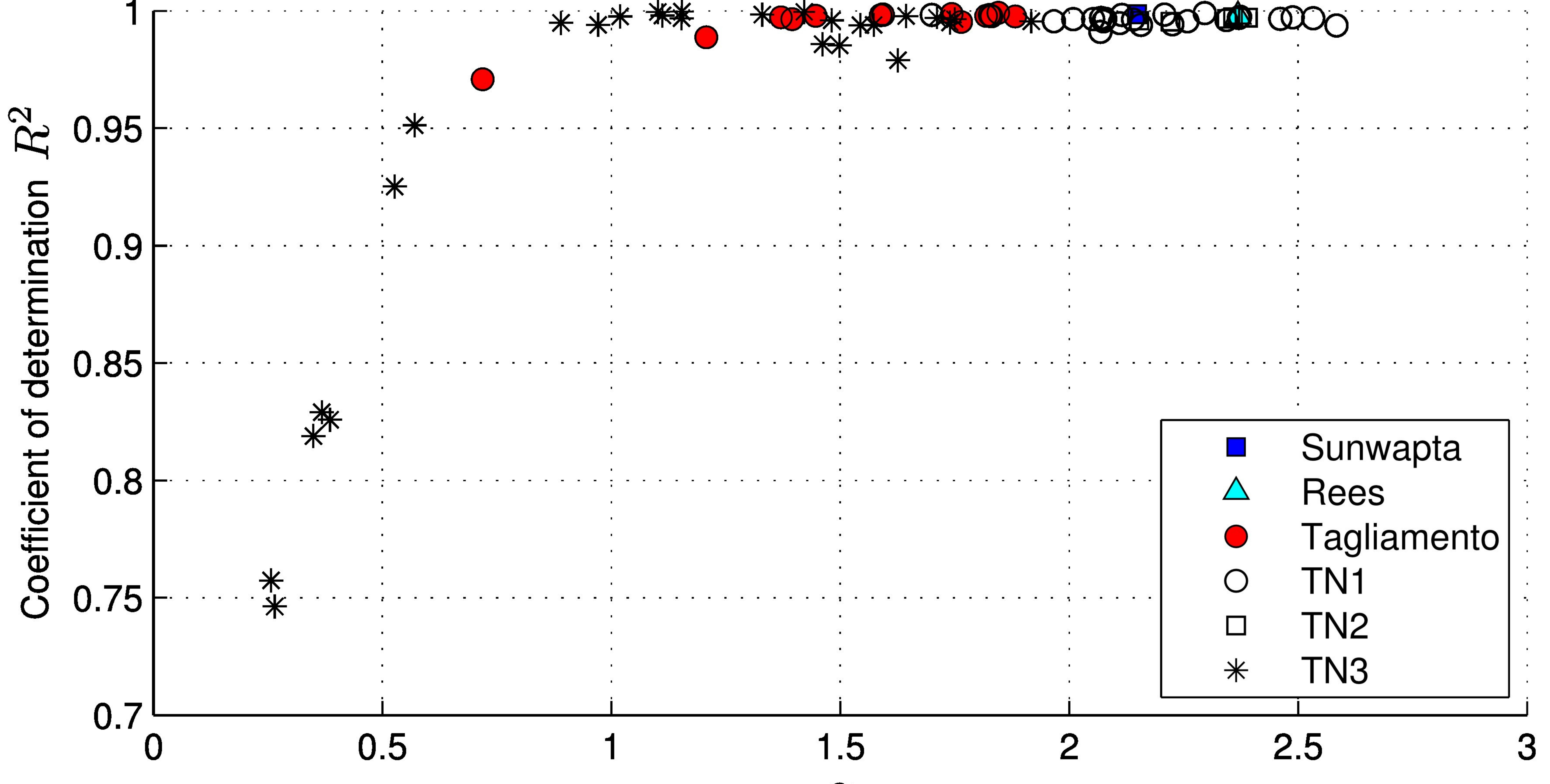




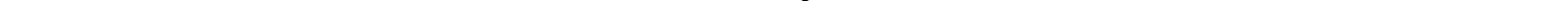



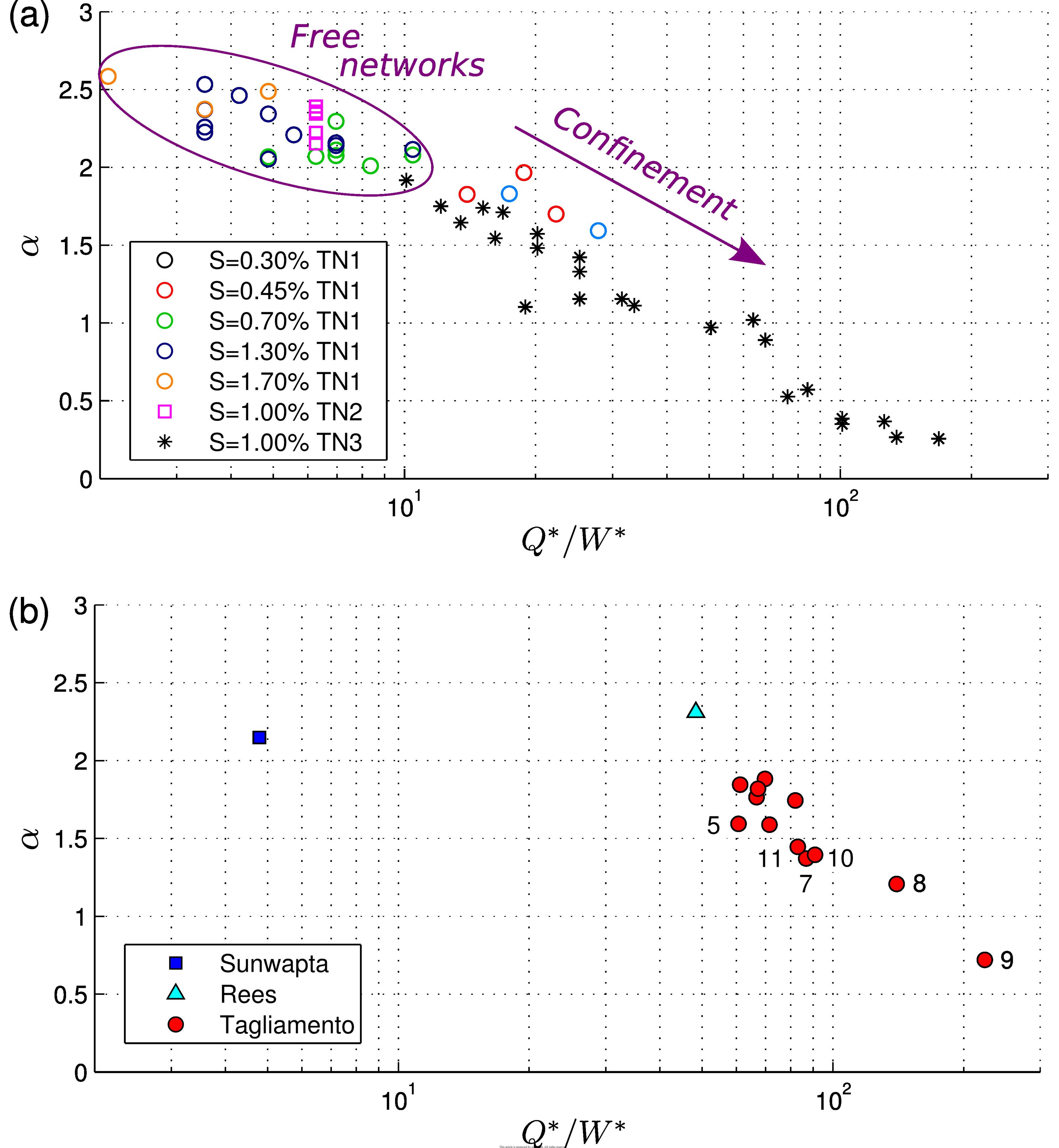
(a)
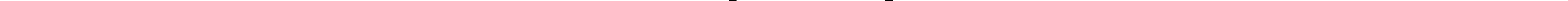
(a)

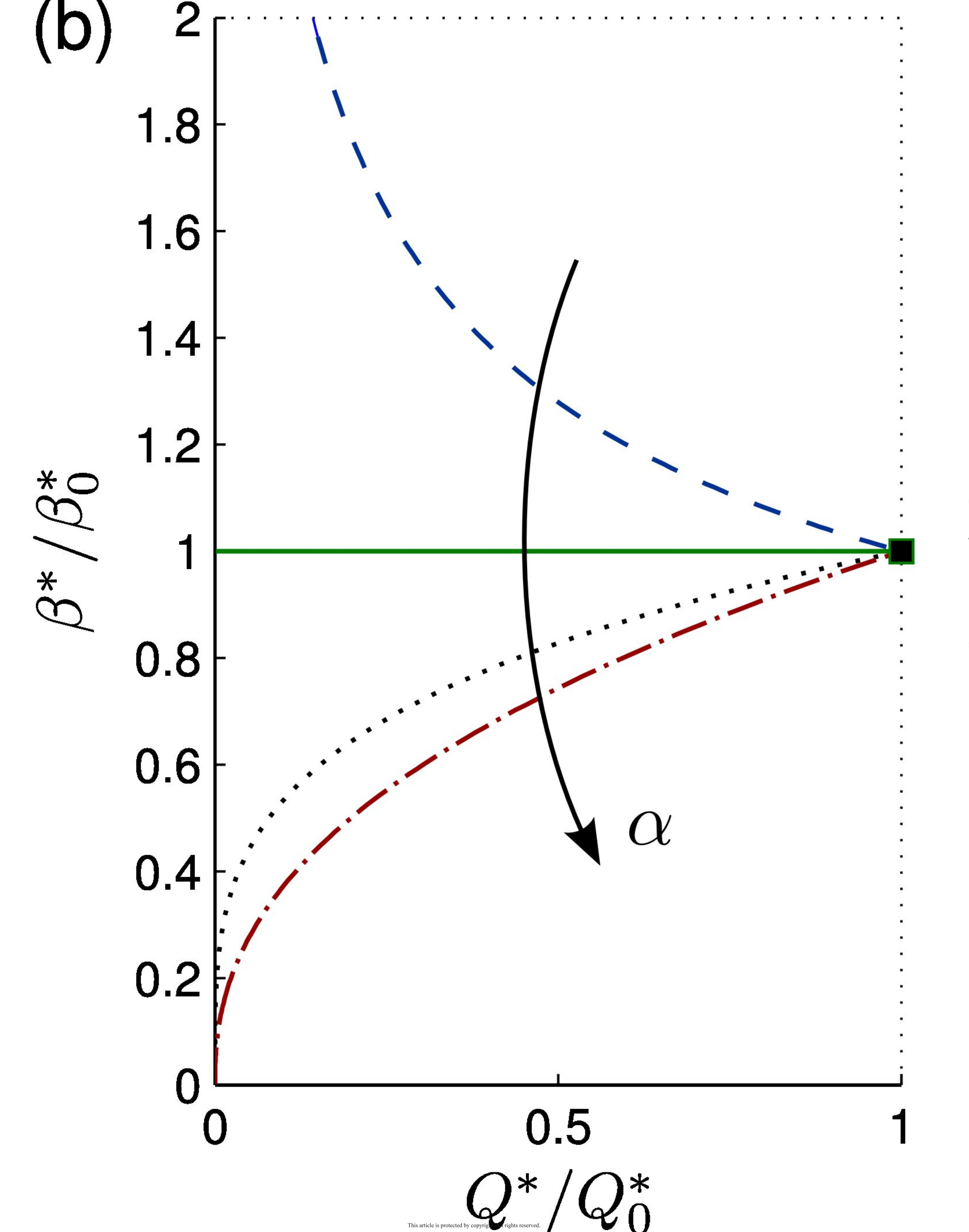

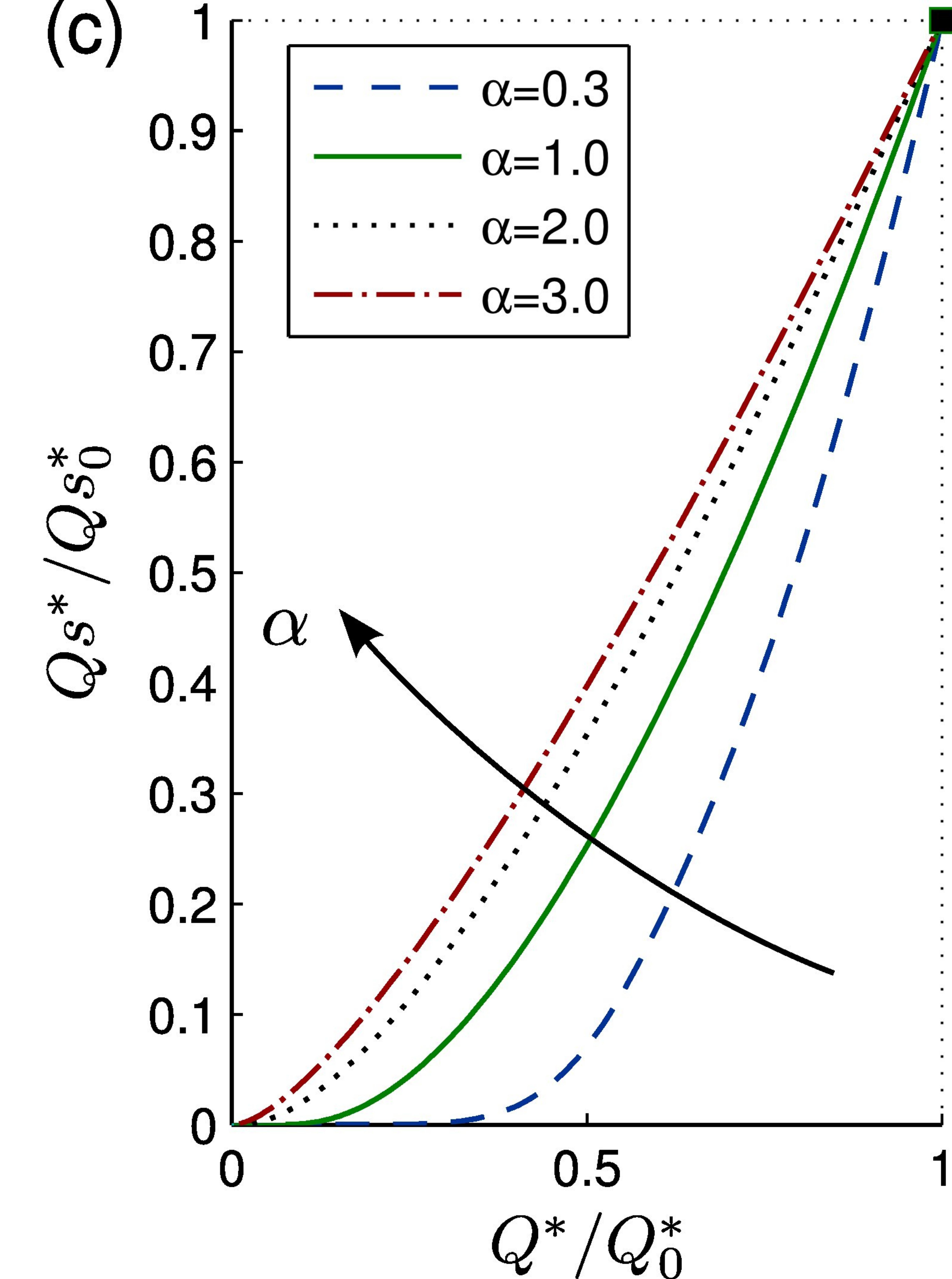

